NBER WORKING PAPER SERIES

\title{
SCHOOL FOOD POLICY AFFECTS EVERYONE: \\ RETAIL RESPONSES TO THE NATIONAL SCHOOL LUNCH PROGRAM
}

\author{
Jessie Handbury \\ Sarah Moshary \\ Working Paper 29384 \\ http://www.nber.org/papers/w29384
}

\author{
NATIONAL BUREAU OF ECONOMIC RESEARCH \\ 1050 Massachusetts Avenue \\ Cambridge, MA 02138 \\ October 2021
}

We would like to thank Lin Fan, Erik James, and Megan Taylor for excellent research assistance and participants at the AREUEA, ASSA-Industrial Organization Society, National Tax Association, NBER Urban Economics Summer Institute, UC Berkeley Opportunity Lab, and Urban Economics Association conferences and the Atlanta Fed, McGill, INRAE, UBC, UC Irvine, and Yale Economics for helpful comments, especially discussants Justin Gallagher, Justine Hastings, Xavier Jaravel, and Adam Kapor. This work is supported by the Robert King Steel Faculty Fellowship at the University of Chicago Booth School of Business and the Research Sponsor's Program of the Zell/Lurie Real Estate Center. Researcher(s) own analyses calculated (or derived) based in part on data from Nielsen Consumer LLC and marketing databases provided through the NielsenIQ Datasets at the Kilts Center for Marketing Data Center at The University of Chicago Booth School of Business. Researcher(s) own analyses calculated (or derived) based in part on data from Nielsen Consumer LLC and marketing databases provided through the NielsenIQ Datasets at the Kilts Center for Marketing Data Center at The University of Chicago Booth School of Business. The views expressed herein are those of the authors and do not necessarily reflect the views of the National Bureau of Economic Research.

At least one co-author has disclosed additional relationships of potential relevance for this research. Further information is available online at http://www.nber.org/papers/w29384.ack

NBER working papers are circulated for discussion and comment purposes. They have not been peer-reviewed or been subject to the review by the NBER Board of Directors that accompanies official NBER publications.

(C) 2021 by Jessie Handbury and Sarah Moshary. All rights reserved. Short sections of text, not to exceed two paragraphs, may be quoted without explicit permission provided that full credit, including () notice, is given to the source. 
School Food Policy Affects Everyone: Retail Responses to the National School Lunch Program Jessie Handbury and Sarah Moshary

NBER Working Paper No. 29384

October 2021

JEL No. H42,I38,L11,R32

\begin{abstract}
We study the private market response to the National School Lunch Program, documenting economically meaningful spillovers to non-recipients. We focus on the Community Eligibility Provision (CEP), an expansion of the lunch program under the 2010 Healthy, Hunger-Free Kids Act. Under the CEP, participating schools offer free lunch to all students. We leverage both the staggered roll-out and eligibility criterion for the CEP, which is limited to schools where at least $40 \%$ of students participate in other means-tested welfare programs. We find that local adoption of the CEP causes households with children to reduce their grocery purchases, leading to a $10 \%$ decline in grocery sales at large retail chains. Retailers respond with chain-level price adjustments: chains with the most exposure lower prices by $2.5 \%$ across all outlets in the years following adoption, so that the program's welfare benefits propagate spatially. Using a stylized model of grocery demand, we estimate that, by 2016, the indirect benefit had reduced grocery costs for the median household by approximately $4.5 \%$.
\end{abstract}

Jessie Handbury

The Wharton School

University of Pennsylvania

1463 Steinberg-Dietrich Hall

Philadelphia, PA 19104

and NBER

handbury@wharton.upenn.edu

Sarah Moshary

University of Chicago

Booth School of Business

5807 S Woodlawn Ave

Chicago, IL 60637

Sarah.moshary@chicagobooth.edu

Latest draft is available at

https://www.dropbox.com/s/nlshhzxuvzhcbi5/\%21 school_lunch_currentpublic.pdf?dl=0 


\title{
School Food Policy Affects Everyone: Retail Responses to the National School Lunch Program*
}

\author{
Jessie Handbury, The Wharton School, University of Pennsylvania ${ }^{\dagger}$ \\ Sarah Moshary, The University of Chicago Booth School of Business ${ }^{\ddagger}$
}

September 21, 2021

\begin{abstract}
We study the private market response to the National School Lunch Program, documenting economically meaningful spillovers to non-recipients. We focus on the Community Eligibility Provision (CEP), an expansion of the lunch program under the 2010 Healthy, Hunger-Free Kids Act. Under the CEP, participating schools offer free lunch to all students. We leverage both the staggered roll-out and eligibility criterion for the CEP, which is limited to schools where at least $40 \%$ of students participate in other means-tested welfare programs. We find that local adoption of CEP leads to a 10\% decline in grocery sales at large retail chains. Retailers respond with chain-level price adjustments: chains with the most exposure lower prices by $2.5 \%$ across all outlets in the years following adoption, so that the program's welfare benefits propagate spatially. Using a stylized model of grocery demand, we estimate that, by 2016, the indirect benefit had reduced grocery costs for the median household by approximately $4.5 \%$.

JEL Codes: H42, I38, L11, R32
\end{abstract}

\section{Introduction}

Food security programs are integral to the U.S. social safety net, exceeding $\$ 90$ billion in 2019. Naturally, a large literature in economics focuses on measuring the welfare benefits

\footnotetext{
${ }^{*}$ We would like to thank Lin Fan, Erik James, and Megan Taylor for excellent research assistance and participants at the AREUEA, ASSA-Industrial Organization Society, National Tax Association, NBER Urban Economics Summer Institute, UC Berkeley Opportunity Lab, and Urban Economics Association conferences and the Atlanta Fed, McGill, INRAE, UBC, UC Irvine, and Yale Economics for helpful comments, especially discussants Justin Gallagher, Justine Hastings, Xavier Jaravel, and Adam Kapor. This work is supported by the Robert King Steel Faculty Fellowship at the University of Chicago Booth School of Business and the Research Sponsor's Program of the Zell/Lurie Real Estate Center. Researcher(s) own analyses calculated (or derived) based in part on data from Nielsen Consumer LLC and marketing databases provided through the NielsenIQ Datasets at the Kilts Center for Marketing Data Center at The University of Chicago Booth School of Business. Researcher(s) own analyses calculated (or derived) based in part on data from Nielsen Consumer LLC and marketing databases provided through the NielsenIQ Datasets at the Kilts Center for Marketing Data Center at The University of Chicago Booth School of Business.

†Contact: handbury@wharton.upenn.edu

$\ddagger$ Contact: sarah.moshary@chicagobooth.edu
} 
these programs provide to their target populations, who typically number among the most vulnerable members of society. The sheer magnitude of these programs suggests that they might also elicit private sector responses that affect the general population. This paper presents new evidence on the impact of public programs on the private sector in the context of the National School Lunch Program (NSLP), which provides meals to children through schools, serving some 30.4 million children in 2016. ${ }^{12}$

The documented benefits of the NSLP for students are substantial, and include higher attendance and test scores (Ruffini (Forthcoming), Schwartz and Rothbart (2020), Frisvold (2015), Schanzenbach (2009), and Bhattacharya and Haider (2006)). We show that the NSLP also reduces household spending at supermarkets when children receive free meals at school. Grocery stores, in turn, adjust product prices. Importantly, and in line with recent descriptive evidence on uniform pricing in U.S. retail (DellaVigna and Gentzkow (2019), Adams and Williams (2019), Hitsch et al. (2019)), we find that price effects propagate through chains such that even communities with low program take-up rates benefit. The indirect benefits enjoyed by all households amount to approximately $10 \%$ of the direct benefit enjoyed by families receiving free lunch.

Our identification strategy exploits the Community Eligibility Provision (CEP), a national program expanding the NSLP under the Healthy, Hunger-Free Kids Act of 2010. Historically, schools collected lunch applications from families to verify individual student eligibility for free or reduced-price lunches. Schools that adopt the CEP need not collect applications, but rather they serve free lunch to all students. The aim of the CEP is to reduce the administrative burden of the lunch program in high-poverty areas, where many students qualify for free lunch under older provisions. In practice, if at least $40 \%$ of a school's enrolled students are categorically-eligible for free school lunch, which means that the students qualify for other means-tested welfare programs, then the school qualifies for the CEP. To be clear, a school where $40 \%$ of students qualify for free lunch under certain older NSLP provisions may now offer all students free lunch-a $150 \%$ increase in the number of free-lunch eligible students. In the 2016-2017 Academic Year, 20,721 schools participated in the NSLP under the CEP, a combined 9.7 million students across 3,538 school districts (Food Research \& Action Center, 2017) ${ }^{3}$ Ruffini (Forthcoming) presents evidence that the program dramatically increased meals served at participating schools, on the order of $12 \%$ for lunches and $38 \%$ for breakfast (because the School Breakfast Program is smaller in scope, we focus primarily on the NSLP, although the CEP integrates similarly with both programs). Our first finding is that the

\footnotetext{
${ }^{1}$ For comparison, the largest domestic hunger safety net program, the Supplemental Nutrition Assistance Program (SNAP), gave an average of $\$ 125.40$ on debit cards to some 44 million recipients in 2016. SNAP restricts allotment spending (e.g. alcohol and to tobacco do not quality), but is far less restrictive than the NSLP.

${ }^{2}$ USDA NSLP Fact Sheet, November 2017.

${ }^{3}$ Program take-up was elective and most eligible schools do not adopt the CEP in our sample period. We exploit the staggered rollout and eligibility cutoff to deal with endogenous participation.
} 
program meaningfully reduces residual demand facing grocery retailers in the private market. Following adoption, households with school-aged children take fewer trips to and spend less money at grocery stores, especially large retail chains. This finding is consistent with evidence from Schanzenbach and Zaki (2014), who show that many marginal students who participate in an experimental free school breakfast program would otherwise eat breakfast at home.

The paper then focuses on understanding how grocery stores respond to the CEP demand shock. We present a simple model of retailer profit maximization, where the CEP serves to reduce the price of a substitute product, the public option. If prices are strategic complements, then the retailer ought to lower the price of store-bought lunch in response to the CEP, generating consumer surplus for adults and children who do not benefit from the CEP directly.4 This prediction is consistent with Cunha et al. (2018), who find that the prices of grocery products fall following the institution of a food delivery program in rural Mexico. However, if prices are strategic substitutes, retailers might instead increase prices. Higher prices would dovetail with findings from the pharmaceutical industry, wherein many branded drugs increase prices when generics enter at low prices (Frank and Salkever, 1992). Whether prices are strategic complements or substitutes depends on whether a reduction in the price of school lunch increases or decreases the own-price demand elasticity for groceries. In theorizing about the impact of the CEP, we also incorporate an insight from the industrial organization literature: namely, that grocery retail chains often employ uniform pricing policies (DellaVigna and Gentzkow (2019), Hitsch et al. (2019), and Adams and Williams (2019)). The CEP presents an opportunity to test the uniform-pricing theory by examining the extent to which prices respond to local adoption of the CEP and/or chain-level exposure to the program. We note that the CEP may also affect upstream firms, such as distributors and wholesalers, but we leave analysis of these affects to future work.

A central concern in estimating the causal effect of the CEP demand shock on grocery retail is selection into the CEP. Because school participation is elective, schools that serve communities where children receive little nutrition at home may be the most likely to join, inducing a correlation between uptake, local grocery revenue, and local grocery prices. We employ two strategies to identify the causal effect of the CEP on grocery stores. First, we compare purchases of households with and without children before and after their local school(s) adopt the CEP. Because adults do not receive food through the NSLP, adultonly households serve as a control group in this comparison. The second strategy exploits two aspects of the program to mitigate endogeneity concerns: the discontinuity in school eligibility at $40 \%$, and the staggered roll-out of the program which became available to different states between 2011 and 2014.

We find that grocery prices fall with the average exposure of a store's retail chain to the

\footnotetext{
${ }^{4}$ Prices are strategic complements (substitutes) if increasing the price of school lunch raises (lowers) the marginal profitability of the price of groceries (Bulow, Geanakoplos, and Klemper 1985.
} 
CEP demand shock. A one standard deviation increase in chain CEP exposure (roughly 8 percentage points) leads to a $2.5 \%$ price reduction across all stores in the chain. In contrast, we find no evidence that prices respond to adoption of the CEP by schools local to the store itself. To our knowledge, this paper is the first to provide empirical evidence that uniform pricing dampens price responses in areas where chain exposure is low, but local adoption is high (and vice versa). Recent work by García-Lembergman (2020) finds similar patterns in retailer price responses to housing market shocks during the Great Recession. One advantage of our setting is that it permits two checks on our empirical strategy that provide confidence in our conclusions: first, and in contrast with price effects, we show that store revenues fall with local rather than chain exposure to the CEP. Second, we show that these revenue declines are largest in categories with high family appeal.

Through the price effects that we document, policies like the NSLP impact the wider community beyond the direct recipients of free school meals. We estimate a stylized model of grocery demand to quantify the welfare benefits of these indirect effects. In the model, households that live near chains with high exposure to the CEP demand shock can benefit from the CEP - even if they do not have school-aged children - through lower prices. The model could also be extended to incorporate extenstive margin responses to the CEP demand shock, although we do not find strong evidence for these in our reduced-form analysis. Our estimates imply that, by 2016, the indirect effect of the CEP amounted to a $4.5 \%$ welfare enhancement for the median household. Our findings highlight a difference between in-kind programs like the NSLP and in-cash programs, where the latter have been shown to harm bystander households (e.g., Filmer et al., 2021, Leung and Seo, 2018, and Hastings and Washington, 2010). In the case of U.S. retail, we note that the use of chain-level pricing facilitates the separate identification of price and distance elasticities, which might be useful in future work seeking to quantify grocery costs using an index that accounts for variation in both the proximity of stores and the prices they charge 5

The rest of the paper proceeds as follows. Section 2 details the Community Eligibility Provision and explores its incentives. Section 4 describes the data. Section 3 presents a simple model of firm pricing as a function of the price of the public lunch option. Section 5 contains our estimation strategy and results on revenues. Results on entry, exit, pricing, and assortment are presented in section 6 . Section 7 quantifies the welfare impacts of price changes in local retail environments. Section 8 concludes.

\section{Background on the National School Lunch Program}

Since 1946, the U.S. Department of Agriculture has administered the National School

5 Eizenberg et al. (2021) also estimate a model of grocery store choice that allows for spatial frictions and price sensitivity. They use this model to study price competition. We instead use our estimates to measure changes in local grocery cost indexes, akin to those calculated in Ellickson et al. (2020) who assume prices are fixed and Atkin et al. (2018) who abstract from within-municipality spatial frictions. 
Lunch Program, which provides nutritious, low-cost meals to students in both public and not-for-profit schools. The program is large; it served some 30.4 million children in 2016. Participating schools receive reimbursements from the federal government for meals served to children from low-income families. Schools may also receive food directly from the USDA. In return, school meals must meet certain nutritional requirements, and low-income students must receive free or reduced rates (40 cents per meal). Paid rates, which are set locally, averaged $\$ 2.63$ per meal in the 2016-2017 academic year.6 Students can qualify for free or reduced price lunches "categorically" if they or their family participate in another meanstested welfare program, including the Supplemental Nutrition Assistance Program. Students can also qualify based on household income and family size, as follows: those below $130 \%$ (130\%-185\%) of the federal poverty line are eligible for free- (reduced-price) lunch.7 To qualify for free or reduced-price lunch based on income, families must submit an application to their school or district. In the 2017-2018 academic year, reimbursements were on the order of $\$ 3.31$ per meal served to a free-lunch student, $\$ 2.91$ for a reduced-price student, and $\$ 0.31$ for a paid student 8 The Community Eligibility Provision, described below, aims at reducing the administrative burden of providing free lunch for high-poverty schools (including application collection and processing).

The CEP is the fourth provision of the National School Lunch Program, rolled out at the state-level between 2011 and 2014 according to the schedule depicted in Table 1. The CEP provides participating schools partial reimbursement for meals served, in return for which it requires that participating schools offer all enrolled students free lunch, regardless of each student's individual financial circumstances.9 Participating schools are reimbursed for meals served according to the school's Identified Student Percentage (ISP), the proportion of students who qualify for the NSLP categorically. The per-pupil reimbursement rate is proportional to 1.6 times the school's ISP. Any school with an ISP above $62.5 \%$ therefore receives the maximum per-pupil funding, while those below must fill the gap left from foregone paid lunch revenues with state or local funding. Central to our identification strategy presented in section 5, a school must have an ISP at or above $40 \%$ to qualify for the provision unilaterally. Schools can also participate as part of a Local Educational Agency (LEA). That is, a school that does not qualify individually can pool with higher-poverty schools, so long as their pooled ISP exceeds $40 \%$.

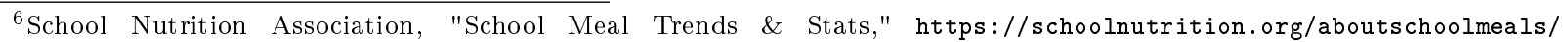
schoolmealtrendsstats/.

'The National School Lunch Program Fact Sheet, USDA, 2017

${ }^{8}$ Schools in Alaska, Hawaii, and Puerto Rico receive additional payments. Schools may also receive an addition 6 cents per pupil if they comply with additional USDA standards. See: Federal Register, July 2018, Vol 83, No 139

${ }^{9}$ Through the CEP, schools can continue to provide meals to students in the summer, e.g., through the USDA Seamless Summer Option or the Summer Food Service Program. See https://www.fns.usda.gov/sfsp/ seamless-summer-and-other-options-schools.
} 
Table 1: Roll-out of the Community Eligibility Provision

\begin{tabular}{ll}
\hline Initial Participation Year & State \\
\hline $2011-2012$ & Illinois, Kentucky, Michigan \\
$2012-2013$ & New York, Ohio, West Virginia, the District of Columbia \\
$2013-2014$ & Georgia, Florida, Maryland, Massachusetts \\
2014-2015 & Remaining States \\
\hline Source: Segal et al. $(2016)$. &
\end{tabular}

\section{How the CEP Might Affect Retail Pricing}

In this section, we illustrate how CEP adoption might affect local grocers, beginning with the household decision of what to buy for lunch. Suppose that each household with schoolage children chooses between school lunch at price $p_{S}$ and grocery store-bought lunch at price $p_{G}$. (For simplicity, suppose that the supermarket sells only a single lunch product.) Let $q\left(p_{G}, p_{S}\right)$ represent the household's demand for grocery-bought lunch. The Community Eligibility Provision affects grocery demand because it lowers $p_{S}$ for some households (those that do not qualify for free lunch under older provisions of the NSLP). Holding grocery prices fixed, the CEP reduces the sales of store-bought lunch so long as the cross-price elasticity is positive:

$$
\frac{\partial q\left(p_{G}, p_{S}\right)}{\partial p_{S}}>0
$$

To understand how the CEP affects supermarket pricing, we aggregate the demand for grocery-bought lunch for households with children $\left(q\left(p_{G}, p_{S}\right)\right)$ with that for households without children, denoting the sum $Q\left(p_{G}, p_{S}\right)$. Grocery store profits are then $\pi\left(p_{G}, p_{S}\right)=$ $\left(p_{G}-c\right) \cdot Q\left(p_{G}, p_{S}\right)$ where $c$ is a constant marginal cost. If grocery and school lunch prices are strategic complements (substitutes), then grocery stores ought to reduce (increase) prices in response to the CEP. Complementarity/substitutability depends on the sign of $\frac{\partial^{2} \pi}{\partial p_{G} \partial p_{S}}$. The first derivative of store profit with respect to own-price gives the familiar first order condition for a Nash Equilibrium in prices:

$$
\frac{\partial \pi}{\partial p_{G}}=Q\left(p_{G}, p_{S}\right)+\left(p_{G}-c\right) \cdot \frac{\partial Q\left(p_{G}, p_{S}\right)}{\partial p_{G}}=0
$$

The cross-derivative is then:

$$
\frac{\partial^{2} \pi}{\partial p_{G} \partial p_{S}}=\frac{\partial Q\left(p_{G}, p_{S}\right)}{\partial p_{S}}+\left(p_{G}-c\right) \cdot \frac{\partial^{2} Q\left(p_{G}, p_{S}\right)}{\partial p_{G} \partial p_{S}}
$$

We expect that the first term is positive, which is to say that as the price of school lunch falls, fewer households will purchase store-bought lunch (per the positive cross-price elas- 
ticity assumed above). Therefore, prices are strategic complements unless the cross-partial $\frac{\partial^{2} Q\left(p_{G}, p_{S}\right)}{\partial p_{G} \partial p_{S}}$ is large and negative. In standard demand models such as the logit, demand becomes more elastic as the market share of a product falls, but we could see the opposite if a decline in the price of school lunch leaves only the wealthiest (demand inelastic) families shopping for lunch at grocery stores. Thus, we turn to empirical analysis to understand how grocers respond to the CEP in practice.

This intuition carries over to a model that incorporates uniform pricing. Recent evidence suggests that retail outlets do not price according to equation (1); instead, chain firms set uniform prices to maximize total profits across all outlets. In the CEP context, prices then ought to respond to the retail chain's overall exposure to the program. From the chain's perspective, the CEP reduces the average price of school lunch $\bar{p}_{S}$ in proportion to program take-up across markets where the chain competes. Uniform pricing implies that prices at some outlets may respond to the CEP even if its nearby schools do not participate in the program. We test for a uniform-pricing response in the empirical analysis below.

\section{Data}

Below we describe the three datasets used in our main analysis: school-level CEP participation and eligibility, purchases and demographics of nearby households, and sales of nearby stores. We complement these data with tract-level demographic data from the American Community Survey (ACS).

\subsection{Program Participation and Eligibility}

Our primary data on CEP participation come from the National Center for Education Statistics (NCES). These data span three academic years: 2013/2014, 2014/2015, and 2015/2016. The NCES contains 70,555 schools across fifty states. We collect earlier participation data from the seven states that adopted the program in 2011/2012 or 2012/2013 from websites and FOIA requests of the individual state Departments of Education.10 We note that the number of participating NCES schools is approximately $30 \%$ lower than the figure reported by the Center for Budget \& Policy Priorities 11 In section 6, we adjust for underreporting when interpreting our results.

For all states, we attempted to gather school-level data on the Identified Student Percentage (ISP), which is used to determine school eligibility for the program. Unfortunately, this data is not available from the early years of the program. Further, districts were required to report ISPs only for eligible schools initially, truncating the distribution of observed ISPs from below.

${ }^{11}$ The CBPP complies participation from lists published by each state for 2015/2016 and 2016/2017, as described in https: //www.cbpp.org/research/food-ass istance/community-eligibility-adoption-rises-for-the-2015-2016-school-year
} 
Figure 1: FRL from the NCES Data Set for the 2009-2010 School Year

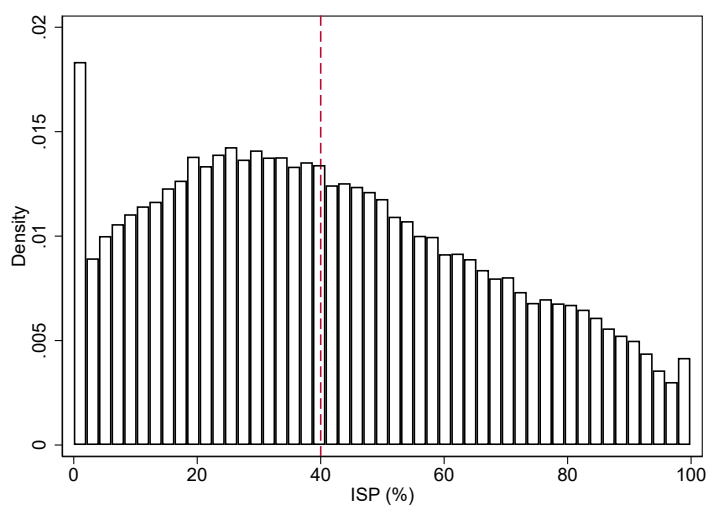

Notes: This figure plots the distribution of the share of students eligible for free and reduced price lunches (FRL) in the 2009-2010 AY. We employ FRL as a proxy for the identified student percentage, ISP, which governs school eligibility for participation in the Community Eligibility Provision.

To measure individual school eligibility for the program, we collect school-level student enrollment and free lunch eligibility rates for academic years 2009/2010 through 2015/2016 from the NCES. We use the fraction of students who qualify for free and reduced-price lunch as a proxy for each school's identified student percentage (ISP). This measure overestimates the true ISP because it includes students who qualify both through direct certification and family income.12 It is therefore a generous measure of individual school eligibility. We favor 2010 ISPs, because in the following year some schools adopt the CEP and thus may report that $100 \%$ of their students are free-lunch eligible (as all students do indeed receive free lunches). Further, because CEP schools do not collect lunch applications, there is no record of which students would have successfully applied under the income requirements. Figure 1 shows the distribution of ISPs across schools in 2009-2010, and it does not reveal any perceptible bunching above the $40 \%$ cutoff. We formally test for manipulation using the methodology in McCrary (2008), and we cannot reject a null hypothesis of no break in the density of ISPs at $40 \%$ (the discontinuity estimate is 0.030 with a standard error 0.024 ). For simplicity, throughout the rest of the paper, we refer to this measure as ISP.

\footnotetext{
${ }^{12}$ A student may be directly certified if their family receives SNAP, FDPIR, TANF; if the student is enrolled in a Head Start program; if the student is homeless, runaway, migrant, or a foster child. (USDA, Community Eligibility: Planning and Implementation Guidance, January 2016.)
} 
Figure 2: School CEP Adoption Share

Full Distribution

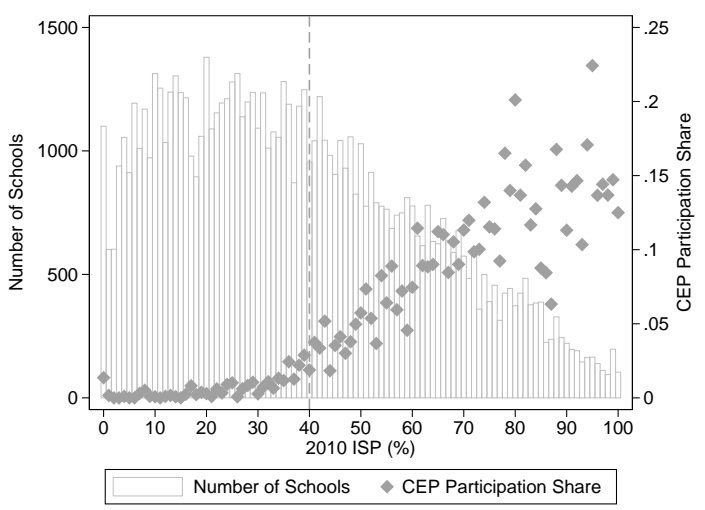

$\mathrm{ISP} \in[30 \%, 50 \%]$

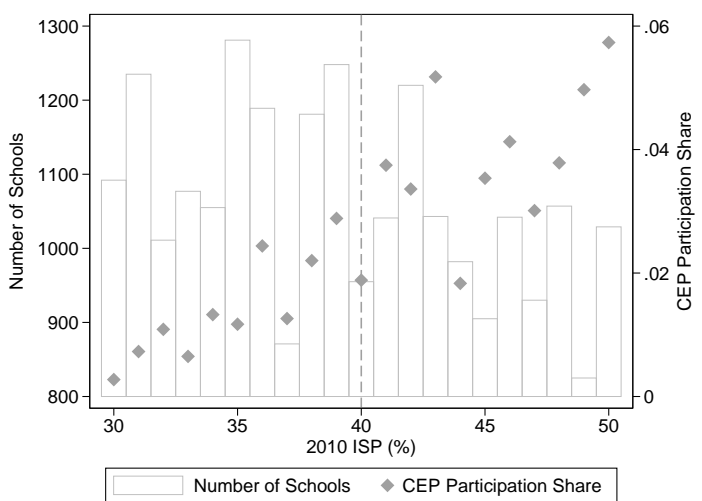

Notes: Each point reflects the share of schools within a given percentile of ISP that participate in the school lunch program. The right-hand plot focuses in on the ISP bins between 30 and 50 .

Figure 2 plots average participation rates for schools at each percentile of ISP for the 2014-2015 Academic Year. Participation rates hover right around zero until 30\%, and then they begin to slope upward. Visual inspection does not suggest a discontinuous increase in participation in the CEP right at $40 \%$. There are two possible reasons that the participation rate is smooth at the $40 \%$ ISP cutoff. First, using a proxy for ISP ought to smooth any jump at the threshold (Pei and Shen, 2017). Second, schools with ISPs below the threshold may participate if they do so as part of a group of schools where the pooled ISP exceeds $40 \%$. For the state of Wisconsin, we collected actual ISP data as well as information on whether schools participated in the CEP individually or as part of a group in the 2016-2017 school year. In these data, there is a sharp discontinuity in individual-school CEP participation at 40\%, and no schools with an ISP below $40 \%$ participated in the program individually. In appendix section B.1, we use these Wisconsin data to implement a fuzzy regression discontinuity design to study the response of lunches served to the CEP in Wisconsin.

Our chief identification strategy involves a difference-in-difference methodology that exploits data on a wider sample of schools (not just those near the threshold) in the years before and after their state introduced the CEP (dates are provided in table 1). The staggered introduction of the CEP across states provides within-year variation in exposure to the program, which Ruffini (Forthcoming) and Gordon and Ruffini (2021) leverage to estimate the effect of the CEP on student performance. Figure 3 plots take-up against ISP separately by number of years since introduction, for different cohorts. The patterns indicate a lag in take-up among eligible schools. Both average adoption rates and the gradient of adoption and ISP appear more pronounced in the second year and beyond. Interestingly, schools in the second wave of state adoptions (New York, Ohio, West Virginia, and Washington, DC) display the strongest kink in participation rates at 40\%; these may be states where our NCES 
ISP proxy aligns more closely with the true ISP.

Figure 3: School CEP Adoption Share by State Adoption Wave
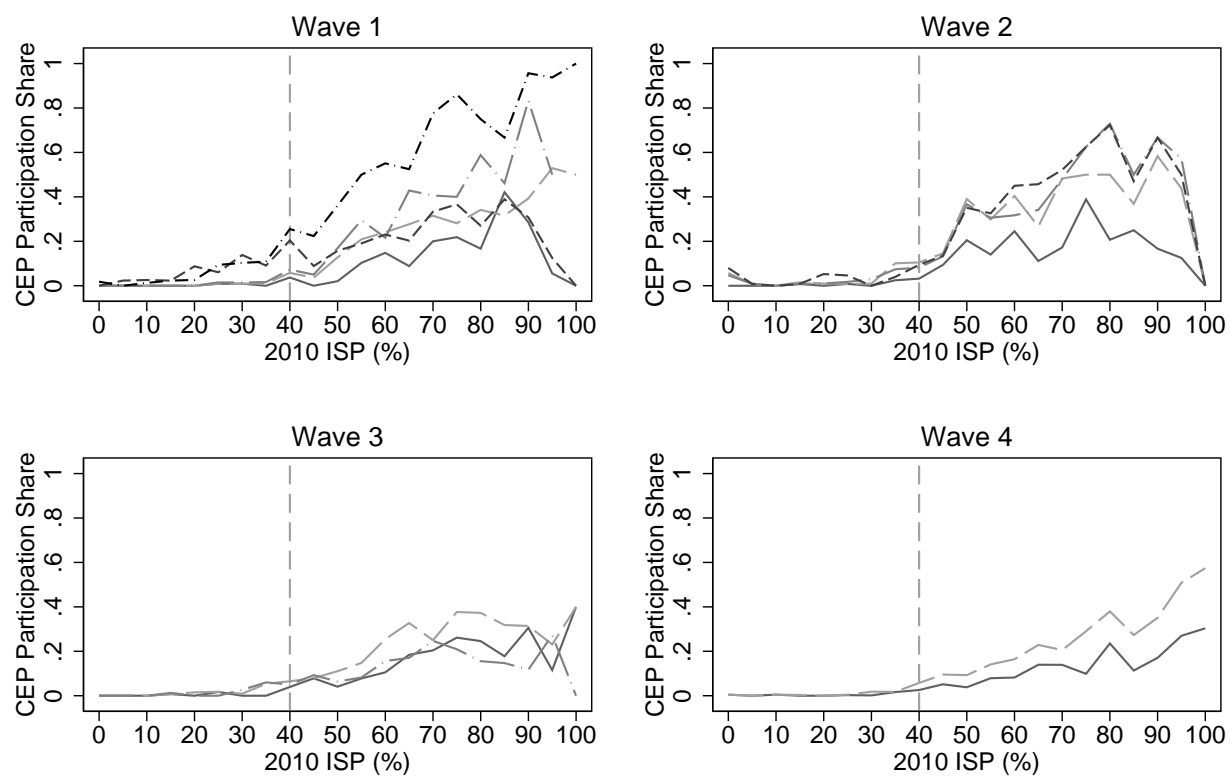

year 1 - - year 2 - - year 3 ----- year 4 - - - year 5

Notes: Wave 1: 2011-2012 (Pilot year. Illinois, Kentucky, Michigan); Wave 2: 2012-2013 (New York, Ohio, West Virginia, DC); Wave 3: 2013-2014 (Georgia, Florida, Maryland, Massachusetts); Wave 4: 2014-2015 (all other states, CEP adopted nationally).

\subsection{Household spending data}

To measure the impact of the CEP on household spending, we use data from Nielsen's Homescan, which contains information on all grocery purchases for a panel of American households from 2011-2016. Table 2 reports summary statistics for the 43,945 panelist households, of which $20 \%$ contain at least one school-age child.13 Crucially, the dataset contains each household's ZIP code. Because we do not know the identity of the school that children within the household attend, we instead measure each household's exposure to the CEP as the average eligibility and participation of schools within the ZIP code where the household resides. The results presented below are robust to measuring eligibility with the average ISP in the household's ZIP code.

\footnotetext{
${ }^{13}$ Our panel is smaller than the raw panel Nielsen panel, since we aggregate household purchases to the academic year and only keep household-years where we observe positive purchases in all 12 months of the academic year.
} 
Table 2: Household Summary Statistics for AY 2014-2015

\begin{tabular}{lcccc}
\hline & Mean & Std. & Min & Max \\
\hline Household Spending & & & & \\
Total Spending (\$ hundreds) & 46.93 & 26.68 & 0.10 & 567.05 \\
Total Grocery Spending (\$ hundreds) & 24.31 & 19.01 & 0.01 & 221.84 \\
Total Lunch Meat Spending (\$ hundreds) & 0.43 & 0.58 & 0.00 & 11.11 \\
& & & & \\
Household Characteristics & & & & \\
Household Size & 2.27 & 1.22 & 1 & 9 \\
Household Income (\$ thousands) & 66.72 & 43.72 & 2.5 & 150 \\
Share of Household with School Age Childeren & 0.16 & 0.37 & 0 & 1 \\
Share of White & 0.84 & 0.37 & 0 & 1 \\
Share of Black & 0.09 & 0.28 & 0 & 1 \\
Share of Asian & 0.03 & 0.18 & 0 & 1 \\
Share of Other Race & 0.04 & 0.19 & 0 & 1 \\
Count & 27,357 & & & \\
\hline
\end{tabular}

Notes: Spending is calculated on an annual basis from September - August in order to align with the academic calendar.

\subsection{Store sales data}

The third data source crucial for our analysis is the Nielsen Scantrack data, which contains weekly sales and quantities by product (Universal Product Code or UPC) collected by pointof-sales systems located in over 20,000 participating grocery stores across the US in 2011 and 201614

Because supermarkets typically stock thousands of products, we construct an inflation index to capture changes in the price of a fixed bundle of goods, whereby avoiding any product heterogeneity biases. Following Beraja et al. (2019), we measure inflation for continuing UPCs: those sold in a given store in every month in the current year and at least one month in the previous year. The calculation proceeds in two steps. First, for each product module $j$, we calculate a month-on-month arithmetic inflation index for each store $s$. Let $u$ denote a particular product (UPC), and $U_{j, s, m}$ be the set of products sold in store $s$ in group $j$ in month $m$. Product-module level inflation for a given month is defined as:

$$
\frac{P_{s, j, m}}{P_{s, j, m-1}}=\frac{\sum_{u \in U_{j, s, m}} p_{u, s, m} q_{u, s, y(m)-1}}{\sum_{u \in U_{j, s, m}} p_{u, s, m-1} q_{u, s . y(m)-1}}
$$

where $p_{u, s, m}$ is the unit price at which UPC $u$ is sold in store $s$ in month $m$ and $q_{u, s, y(m)-1}$

\footnotetext{
${ }^{14}$ The Nielsen data is provided by the Kilts-Nielsen Data Center at the University of Chicago Booth School of Business; refer to http://research.ChicagoBooth.edu/nielsen for information on availability and access.
} 
is the quantity of UPC $u$ sold in store $s$ in the calendar year preceding month $m$. We then aggregate across product modules using a Tornqvist index:

$$
\frac{P_{s, m}}{P_{s, m-1}}=\prod_{j \in J}\left(\frac{P_{s, j, m, y}}{P_{s, j, m-1, y}}\right)^{\frac{S_{s, j, m}+S_{s, j, m-1}}{2}}
$$

where $S_{s, j, m}$ denotes the expenditure share of product module $j$ in store $s$ in month $m$. Storelevel monthly inflation is therefore a Tornqvist aggregate of Laspeyres-style lagged-weight arithmetic indexes at the product module-store level. To obtain the price level of each store $s$ in month $m, P_{s, m}$, we take a rolling average of store-level monthly inflation from January 2010, during which the index is set to 1 .

To study how store prices and revenues respond to CEP participation, we aggregate the data to the annual level, with each year running from September to August to reflect the academic calendar. Sales for the 2014-2015 school year, for example, are total sales from September 2014 to August 2015, while the price index is the average of the monthly price index $P_{s, m}$ over the same period. We calculate revenue and price indexes for breakfast and lunch foods separately, where we hand-code product categories based on Nielsen descriptions. See Appendix table 13 for a list of breakfast and lunch foods groups. In our main analysis, we focus on grocery stores because they account for the lion's share of breakfast and lunch spending.15

For each store $i$, we calculate exposure to the CEP as the average participation and eligibility of the schools that share the same ZIP code. Table 3 contains summary statistics on stores as well as the schools in our sample in the $2014 / 2015$ school year.

\footnotetext{
${ }^{15}$ We also limit the sample to stores for which we have a breakdown of sales by breakfast and lunch foods.
} 
Table 3: Summary Statistics for the 2014-2015 School Year

\begin{tabular}{|c|c|c|c|c|}
\hline & Mean & Std. & Min & Max \\
\hline \multicolumn{5}{|l|}{ Store Characteristics } \\
\hline Annual Revenue (\$ millions) & 1.58 & 0.90 & 0.14 & 10.26 \\
\hline Lunch and Breakfast Revenue ( $\$$ millions) & 0.50 & 0.28 & 0.00 & 3.06 \\
\hline Lunch Meat Revenue (\$ millions) & 0.02 & 0.01 & 0.00 & 0.18 \\
\hline Price Index: All Goods & 1.46 & 0.20 & 1.05 & 2.94 \\
\hline Count & 5,575 & & & \\
\hline \multicolumn{5}{|l|}{ Zipcode Characteristics } \\
\hline Average NCES ISP Proxy ( $\%$ of enrollment) & 42.03 & 49.37 & 0.00 & 100.00 \\
\hline Average I[NCES ISP > 40\%] & 40.49 & 39.64 & 0.00 & 100.00 \\
\hline Average Participation Rate (\%) & 12.89 & 27.75 & 0.00 & 100.00 \\
\hline Zip Chain AvgEligible & 0.46 & 0.10 & 0.05 & 0.94 \\
\hline Zip Chain PartCEP & 1.34 & 0.70 & -0.77 & 3.56 \\
\hline Zip Chain PartCEP & 0.13 & 0.04 & 0.00 & 0.26 \\
\hline Household Annual Income & 67.62 & 26.56 & 13.85 & 208.13 \\
\hline Share of African American Population & 8.37 & 14.20 & 0.00 & 97.20 \\
\hline Zip Price Index: All Goods & 1.47 & 0.19 & 1.07 & 2.99 \\
\hline Average number of Nielsen Stores & 1.42 & 0.82 & 0.00 & 6.00 \\
\hline Average number of CBP Stores & 5.80 & 5.03 & 0.00 & 61.00 \\
\hline Count & 3,279 & & & \\
\hline \multicolumn{5}{|l|}{ Chain-Level Characteristics } \\
\hline Average NCES ISP Proxy ( $\%$ of enrollment) & 38.94 & 25.71 & 0.00 & 100.00 \\
\hline Average I[NCES ISP > 40\%] & 40.83 & 22.63 & 5.32 & 94.23 \\
\hline Average Participation Rate (\%) & 6.07 & 8.45 & 0.00 & 50.87 \\
\hline Count & 57 & & & \\
\hline
\end{tabular}

Notes: Store summary statistics based on a balanced panel of grocery retailer sales in the Nielsen ScanTrack data (2010-2016). ZIP code and chain characteristics from ScanTrack and NCES data.

\section{The CEP Demand Shock Evidence from Households}

We begin by documenting how the CEP changes demand for groceries. Specifically, we present evidence that the direct beneficiaries of the program (households with school-age children) reduce their expenditures when their neighboring schools adopt the CEP. Because adoption may be correlated with other time-varying factors that directly affect grocery spending, we use adult-only households as a control group for those households with school-age children (only the latter are directly affected by the CEP). The identification assumption is that these households are equally affected by any relevant time-varying factors.

Our regression specification is:

$$
\ln E_{h t}=\gamma_{0}+\gamma_{1} \cdot C E P_{s(h), t}+\gamma_{2} \cdot C E P_{s(h), t} \times K i d_{h}+\Gamma_{h}+\Omega_{t} \times \text { State }_{h}+\epsilon_{h t}
$$


where $E_{h t}$ is the sum of household $h$ 's expenditures in year $t ; K i d_{h}$ is an indicator for whether household $h$ includes a school-age child; $C E P_{s(h), t}$ is the weighted average CEP adoption of the elementary, middle, and high schools nearest to household $h$ 's ZIP centroid at time $t$; and $\Gamma_{h}$ are household fixed effects, which control for time-invariant differences in spending across households. Results are presented in table 4 a. In even-numbered columns, we include a triple interaction of $C E P_{s(h), t} \times K i d_{h} \times \ln \left(\right.$ Income $\left._{h}\right)$, with an eye towards understanding which households substitute from store-bought lunch to school lunch when the CEP is introduced. In theory, the lowest income households already receive lunch for free, and so adoption of the CEP for this group could operate only through stigma; because of its link to family finances, these eligible students may have been embarrassed to receive free school lunch under the traditional NSLP (Moffitt, 1983). In contrast, for higher income households, the CEP changes the relative price of the two goods.

The baseline results, presented in column 1 of table 4 a, suggest that the CEP reduces grocery store expenditures of households with school aged children by around $7 \%$ relative to households without children. This difference is both economically and statistically significant (approximately $\$ 200$ annually - approximately two weeks of recorded grocery spending - for households in our sample). The results do not speak to heterogeneity across income groups: the triple interaction term in column 2 is statistically insignificant and the confidence interval is wide. Columns 3 and 4 shows similar effects for product modules that we categorize as breakfast and/or lunch foods (see appendix table 13 for a list of products). Columns 5 and 6 show that CEP adoption lowers the number of shopping trips undertaken by households with school-aged children by $6-7 \%$.

Table $4 \mathrm{~b}$ replicates these results focusing only on expenditures at and trips to the Nielsen RMS grocery retailers, which tend to belong to larger chains. Households with school-age children reduce their grocery expenditures at RMS retailers by $13 \%$ relative to households without school-aged children and reduce their trips by over $6 \%$. The outsized effects at Nielsen retailers suggests that the substitution towards free school lunch causes households to substitute towards smaller, independent retailers for their remaining grocery shopping needs. 
Table 4: Effect of the CEP on Household Spending

\begin{tabular}{|c|c|c|c|c|c|c|}
\hline & \multicolumn{2}{|c|}{ Food Expenditures } & \multicolumn{2}{|c|}{ B/L Expenditures } & \multicolumn{2}{|c|}{ Number of Grocery Trips } \\
\hline & $(1)$ & $(2)$ & $(3)$ & (4) & $(5)$ & (6) \\
\hline CEP & $\begin{array}{c}0.021^{*} \\
(0.011)\end{array}$ & $\begin{array}{c}0.025^{* *} \\
(0.011)\end{array}$ & $\begin{array}{c}0.019 \\
(0.012)\end{array}$ & $\begin{array}{c}0.023^{*} \\
(0.012)\end{array}$ & $\begin{array}{c}0.013 \\
(0.008)\end{array}$ & $\begin{array}{c}0.018^{* *} \\
(0.008)\end{array}$ \\
\hline CEP x School Age Kid & $\begin{array}{c}-0.066^{* *} \\
(0.028)\end{array}$ & $\begin{array}{c}-0.070^{* *} \\
(0.028)\end{array}$ & $\begin{array}{c}-0.072^{* *} \\
(0.029)\end{array}$ & $\begin{array}{c}-0.075^{* *} \\
(0.029)\end{array}$ & $\begin{array}{c}-0.067^{* * *} \\
(0.021)\end{array}$ & $\begin{array}{c}-0.072^{* * *} \\
(0.021)\end{array}$ \\
\hline CEP x ln(Income) & & $\begin{array}{c}0.030^{* *} \\
(0.013)\end{array}$ & & $\begin{array}{c}0.028^{* *} \\
(0.014)\end{array}$ & & $\begin{array}{c}0.030^{* * *} \\
(0.010)\end{array}$ \\
\hline CEP x School Age Kid x $\ln ($ Income $)$ & & $\begin{array}{c}-0.034 \\
(0.033) \\
\end{array}$ & & $\begin{array}{l}-0.036 \\
(0.035) \\
\end{array}$ & & $\begin{array}{c}-0.019 \\
(0.028) \\
\end{array}$ \\
\hline R-Squared & 0.859 & 0.859 & 0.851 & 0.851 & 0.868 & 0.868 \\
\hline Observations & 249,064 & 249,064 & 249,064 & 249,064 & 249,064 & 249,064 \\
\hline \multicolumn{7}{|c|}{ Panel b: Expenditure and Trips to RMS Stores } \\
\hline & \multicolumn{2}{|c|}{ Food Expenditures } & \multicolumn{2}{|c|}{ B/L Expenditures } & \multicolumn{2}{|c|}{ Number of Grocery Trips } \\
\hline & (1) & $(2)$ & (3) & $(4)$ & $(5)$ & $(6)$ \\
\hline CEP & $\begin{array}{c}0.050^{* *} \\
(0.021)\end{array}$ & $\begin{array}{c}0.055^{* * *} \\
(0.021)\end{array}$ & $\begin{array}{c}0.047^{* *} \\
(0.022)\end{array}$ & $\begin{array}{c}0.052^{* *} \\
(0.023)\end{array}$ & $\begin{array}{l}0.016^{*} \\
(0.009)\end{array}$ & $\begin{array}{c}0.022^{* *} \\
(0.009)\end{array}$ \\
\hline CEP x School Age Kid & $\begin{array}{c}-0.134^{* * *} \\
(0.050)\end{array}$ & $\begin{array}{c}-0.136^{* * *} \\
(0.050)\end{array}$ & $\begin{array}{c}-0.160^{* * *} \\
(0.053)\end{array}$ & $\begin{array}{c}-0.163^{* * *} \\
(0.053)\end{array}$ & $\begin{array}{c}-0.067^{* * *} \\
(0.024)\end{array}$ & $\begin{array}{c}-0.072^{* * *} \\
(0.023)\end{array}$ \\
\hline CEP x $\ln$ (Income) & & $\begin{array}{c}0.030 \\
(0.020)\end{array}$ & & $\begin{array}{c}0.030 \\
(0.022)\end{array}$ & & $\begin{array}{c}0.039^{* * *} \\
(0.011)\end{array}$ \\
\hline CEP x School Age Kid x $\ln ($ Income $)$ & & $\begin{array}{l}-0.065 \\
(0.071) \\
\end{array}$ & & $\begin{array}{l}-0.058 \\
(0.074) \\
\end{array}$ & & $\begin{array}{c}-0.050^{*} \\
(0.030) \\
\end{array}$ \\
\hline R-Squared & 0.844 & 0.844 & 0.835 & 0.835 & 0.87 & 0.87 \\
\hline Observations & 185,267 & 185,267 & 185,267 & 185,267 & 185,267 & 185,267 \\
\hline
\end{tabular}

Notes: Standard errors, clustered at the ZIP level, in parentheses. All specifications include state-by-year and household fixed effects. All outcomes are measured in logarithms. Log income is de-meaned. All specifications include an indicator for whether the household includes a school-aged child.

Figure 4 illustrates this difference-in-differences strategy by showing the difference in spending between households with and without kids each year, before and after their local school adopts the CEP ${ }^{16}$ Before adoption, the spending difference between households with school-age children relative to those without is fairly stable. Consistent with a causal effect, statistically detectable differences emerge only after the CEP is introduced.

These estimates imply a substantive effect of the CEP on grocery demand. Households with school-age children comprise approximately $50 \%$ of the population, so that grocery stores adjacent to schools that take-up CEP would expect at least a $4 \%$ decline in overall sales.17 In the next section, we explore how grocery stores respond to this shift in their residual demand curves.

\footnotetext{
${ }^{16}$ For visual simplicity, we code each household's exposure as binary here by considering a households treated if its nearest school adopts the CEP.

17 https://nces.ed.gov/programs/digest/d09/tables/dt09_019.asp. Assuming that the average household with children spends more on groceries than the typical adult-only household.
} 
Figure 4: Spending Differences between Household with/without a School-Aged Child

(a) Grocery - Food

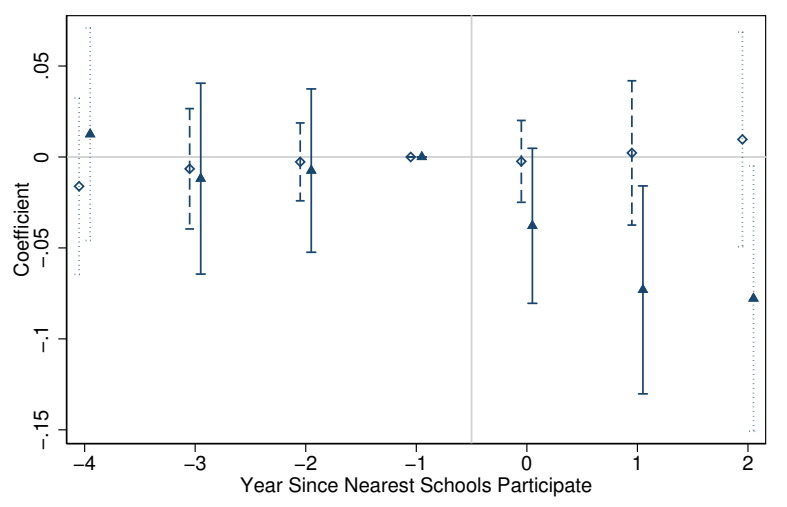

^ Households with School-Age Kid $\diamond$ Households without School-Age Kid (b) Grocery - Breakfast/Lunch

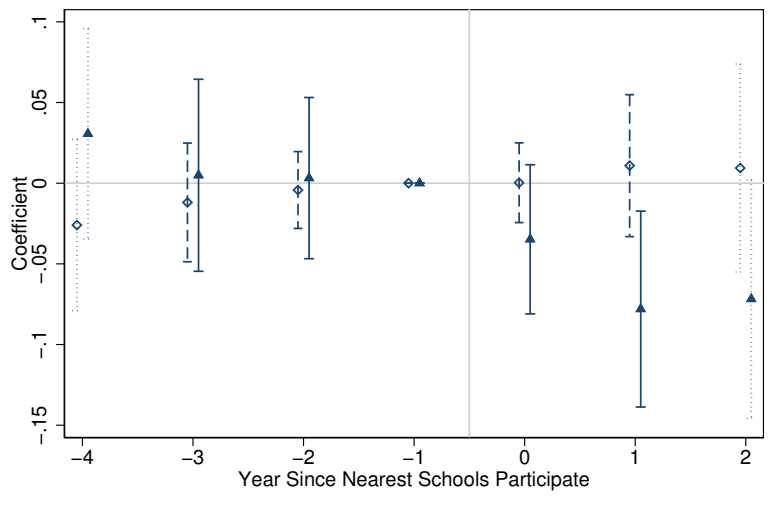

$\Delta$ Households with School-Age Kid $\diamond$ Households without School-Age Kid

(c) Grocery - Number of Trips

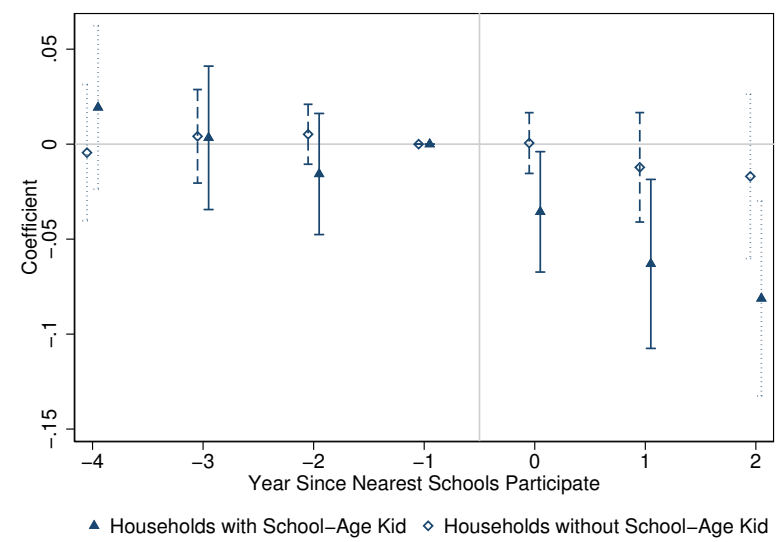

Notes: Using 2007-2017 Homescan data, these figures present the treatment effect of CEP participation on household food and breakfast/lunch expenditures and number of grocery shopping trips. The data includes only the households with the nearest school that has ever participated in the program. All regressions control for state-by-year and household fixed effects. Standard errors are clustered at the ZIP level. The academic years beyond $[t-4, t+2]$ are binned up on both ends to ensure balanced panel of data, where $t$ denotes the year of participation.

\section{Retailer Responses to the CEP}

We now turn to our main object of interest: the supply-side response to the Community Eligibility Provision, with a focus on whether and to what extent retailers adjust prices. Our results in section 5 show that the average household with school-aged children reduces expenditures in RMS grocery stores by as much as $15 \%$ when their neighboring school adopts the CEP, extending free lunch and breakfast to all students. Our results are consistent with 
substitution away from home-made lunch (a positive cross-price elasticity). The conceptual framework that we developed in section 3 highlights that, by changing the demand elasticity for groceries, the CEP may cause retailers to increase or decrease prices-whether or not retailers engage in uniform pricing. Because CEP adoption is endogenous to local economic conditions, we exploit the discontinuity in CEP eligibility rules to identify how the program affects store pricing decisions.

\subsection{Econometric Model}

We model the price index of store $i$ in year $t$ as a function of the CEP participation rates of neighboring schools (in the same ZIP code) in that year. We also include store fixed effects $\Omega_{i}$ and year-by-county fixed effects $\Gamma_{t} \times \Delta_{\text {county(i) }}$ to pick up any time-invariant drivers of store revenue (e.g., store size) and any county-wide shocks to spending, 18 Our specification of interest is therefore:

$$
y_{i t}=\beta_{0}+\beta_{1} \cdot C E P_{i t}+\Omega_{i}+\Gamma_{t} \times \Delta_{\text {county }(i)}+\epsilon_{i t} .
$$

If grocery stores adjust prices when their local school adopts the CEP, then $\beta_{1} \neq 0$.

We present estimates of (3) in column 1 of table 5. The coefficient on the CEP adoption rate suggests that neighboring school participation reduces grocery store prices on the order of $0.9 \%$. The drop is less pronounced for the breakfast/lunch category and for lunch meat in particular. We do not interpret these estimates of equation (3) as causal, because participation in the CEP is elective. Our concern is that schools might select into the program on the basis of local economic trends (more granular than at the county level), potentially confounding OLS estimates. To identify a causal effect of the CEP, we adopt a differencein-differences approach.

Table 5: OLS Results of Prices on CEP Adoption

Notes: Standard errors in parentheses. ${ }^{*} p<0.1,{ }^{* *} p<0.05,{ }^{* * *} p<0.01$. All regressions include store and county-year fixed effects. Standard errors are clustered at store level. Price indices are aggregated to the school year, with sales from September 2014 to August 2015, for example, being associated with CEP participation in the 2014/2015 school year.

Our estimation strategy exploits two features of the CEP: the staggered roll-out of the CEP across four waves, and the requirement that a school's ISP equal or exceed $40 \%$ to

\footnotetext{
${ }^{18}$ A second motivation for including county-by-year FE are concerns raised in Sun and Abraham (Forthcoming) and GoodmanBacon 2021. Including these FE narrows the control group in our analysis to other stores within the same wave.
} 
qualify for the provision 19 The first source of identifying variation allows us to construct an estimator that compares changes in store prices in early and late adopting states. This is similar to the identification in Hoynes and Schanzenbach (2009), who study the effect of SNAP on food spending. Our chief concern is that early-adopting states may differ systematically from late adopters in ways that affect year-to-year changes in store prices. We therefore construct a difference-in-differences estimator using the $40 \%$ ISP eligibility requirement.

In our preferred specification, stores near schools below the $40 \%$ threshold act as controls for those near schools above the threshold. This strategy is similar in spirit to a regression discontinuity design, but it exploits the entire dataset rather than the set of schools near the threshold. ${ }^{20}$ Our identification assumption is that changes in the relationship between ISP and an outcome of interest below/above $40 \%$ are driven by the CEP, rather than changes in the underlying characteristics of those stores.

Our preferred specification for an outcome $y$ for store $i$ is:

$$
\begin{aligned}
y_{i t} & =\alpha_{0}+\alpha_{1} \cdot 1[\text { StateAdopt }]_{i t}+\alpha_{2} \cdot 1[\text { StateAdopt }]_{i t} \times \text { shareISP } 40_{i} \\
& +\Omega_{i}+\Gamma_{t} \times \Delta_{\text {county }(i)}+\omega_{i t}
\end{aligned}
$$

where $1[\text { StateAdopt }]_{i t}$ is an indicator that store $i$ 's state had adopted the CEP by year $t$ and shareISP40 $i$ is the share of neighboring schools with an 2010 ISP of 40 or above. The coefficient of interest is $\alpha_{2}$, which governs the relationship between prices and the interaction between the ISP threshold and state adoption. The coefficient $\alpha_{2}$ therefore captures an intent-to-treat effect of the CEP: the change in price for local stores when their nearest school becomes eligible for the program. Our baseline specification includes store fixed effects, which control for time-invariant determinants of pricing, and county-by-year fixed effects, which control for county-wide shocks to the grocery industry. Importantly, all variants of this specification allow the relationship between ISP and store prices to differ systematically across early and late adopting states for reasons apart from the CEP. The identifying assumption is that any change in this relationship at $40 \%$ stems from differences in CEP eligibility.

In our preferred specification, we adapt equation (4) to allow for an important feature of grocery retail in the U.S.. As described in DellaVigna and Gentzkow (2019), among others, most retail chains featured in the Nielsen dataset employ uniform pricing, wherein prices for the same product (UPC) do not vary across broad geographical regions. Uniform pricing implies that any individual grocery outlet is unlikely to adjust prices in response to a local CEP demand shock. However, a retail chain that is highly exposed to the CEP may adjust

\footnotetext{
${ }^{19}$ Or group of schools', termed an LEA.

${ }^{20}$ Recall that RDD is not feasible given our proxy for ISP precise measurement of the running variable $($ Pei and Shen 2017$)$ ).
} 
prices across a broad swathe of stores. In other words, a chain with a high share of stores that experience the CEP demand shock may respond along the price margin, changing prices even in stores that are not directly exposed themselves.

To test the uniform pricing hypothesis, we construct chain-level analogues of CEP adoption (the average adoption of retail outlets in the chain) and exposure (the average neighboring school CEP eligibility of retail outlets in the chain). In our augmented specification, we examine whether individual retailer and/or chain exposure affects pricing.

\subsection{Price Responses}

Table 6 presents results of local store-level and chain-wide exposure to CEP adoption on prices. Columns 1 and 3 show a null effect of local store-level exposure on prices (point estimates are below 1\%). In contrast, we find a robust negative effect of chain exposure on price, whether or not we control for local exposure (columns 2 and 3). A one-standard deviation increase in chain exposure leads to a $2.3 \%$ decline in the price index.

We present the results graphically in figure 5. The left panel shows how prices drop over time for chains with high average eligibility, measured as the share of stores that operate near schools with an ISP $\geq 40$, relative to chains with low average eligibility. Consistent with the staggered roll-out of the CEP between 2011-2014, prices decline gradually. The right panel shows how prices evolve for stores that neighbor eligible vs ineligible schools before and after the state adopts the program. We see no evidence of price changes in response to local exposure.

Table 6: Effect of CEP Exposure on Prices

\begin{tabular}{lccccccc}
\hline \hline & \multicolumn{3}{c}{ All } & & \multicolumn{3}{c}{$\mathrm{B} / \mathrm{L}$} \\
\cline { 2 - 5 } \cline { 6 - 8 } & $(1)$ & $(2)$ & $(3)$ & & $(4)$ & $(5)$ & $(6)$ \\
\hline State Adopt x Store & 0.001 & & 0.007 & & $-0.006^{*}$ & & -0.000 \\
Zip Percent Eligible & $(0.005)$ & & $(0.005)$ & & $(0.003)$ & & $(0.003)$ \\
Chain Average of & & $-0.022^{* * *}$ & $-0.023^{* * *}$ & & $-0.022^{* * *}$ & $-0.022^{* * *}$ \\
(State Adopt x Store Zip Percent Eligible) & & $(0.003)$ & $(0.003)$ & & $(0.003)$ & $(0.003)$ \\
\hline Observations & 53,059 & 53,059 & 53,059 & & 53,059 & 53,059 & 53,059 \\
R-Squared & 0.897 & 0.897 & 0.897 & & 0.903 & 0.904 & 0.904 \\
\hline \hline
\end{tabular}

Notes: Outcome variable is a price index constructed using store-weights. Standard errors in parentheses. ${ }^{*} p<0.1,{ }^{* *} p<0.05,{ }^{* * *} p<0.01$. All regressions include store and county-year fixed effects. Standard errors are clustered at store level. The price index is constructed at the school year, with sales from September 2014 to August 2015, for example, being associated with CEP participation in the 2014/2015 school year. Chain exposure is normalized. 
Figure 5: Effect of CEP Eligibility Exposure on Prices

(a) Chain-Level Exposure

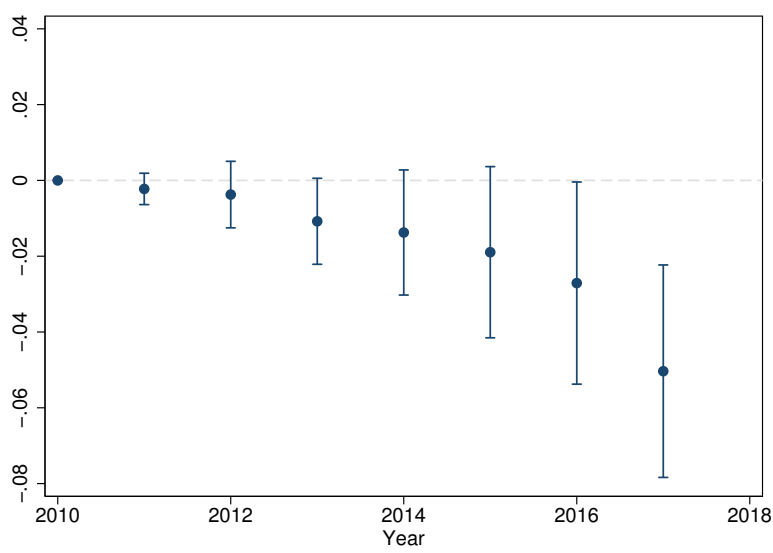

(b) Store-Level Exposure

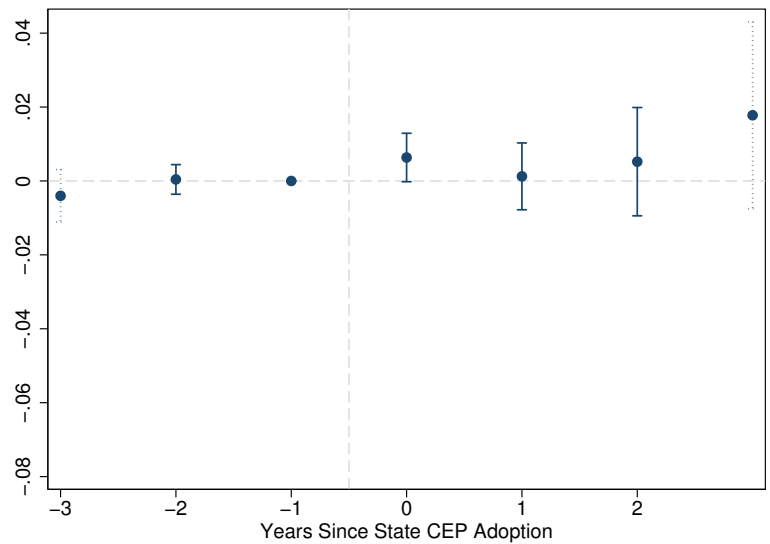

Notes: Plots regression coefficients from a specification that includes store and county $\times$ year FE. In addition, plot 5 a controls for local eligibility to the CEP and plot $5 \mathrm{~b}$ controls for chain exposure. Local CEP eligibility is an enrollment-weighted average of the eligibility of the elementary, middle and high school nearest to the store's ZIP code centroid. Chain exposure is measured as the average of the enrollment-weight average eligibility of schools that neighbor stores in the chain (we normalize this measure for ease of interpretation).

These results offer two implications: first, they suggest that the spillovers of the CEP are substantial, lowering prices for households with and without children. If redistribution to consumers in areas with high-exposure chains but low rates of local adoption is desirable, then these spillovers present an argument in favor of in-kind giving. Second, they provide evidence for how market structure-in particular, the configuration of retail chains-affects the propagation of demand shocks in the economy. Relative to other work studying the effects of demand shocks on prices (e.g., Leung and Seo, 2018 and Stroebel and Vavra, 2019), our results confirm that effects can be large, but they also suggest that these effects depend crucially on the spatial distribution of chains.

\subsection{Impact of the CEP on Store Revenue}

We next document how store and chain CEP exposure affects retailer revenues. Examining revenues provides a check on our econometric model in two ways. First, we confirm that local rather than chain CEP exposure reduces store revenues. While uniform pricing implies that CEP price effects ought to propagate across chains, the first order effect of the CEP on revenue ought to come from a reduction in grocery demand in stores near households with children who attend schools that adopt the CEP. Second, we reconcile estimated CEP retailer revenue effects with the estimated household expenditure effects described in section 5 . providing reassurance that the difference-in-difference identifies the causal effect of the 
CEP.

We report our baseline estimates of specification 4 in table 7 and the graphical analogue in figure 6. The coefficient in column 1 implies that stores near schools that are all eligible for the CEP earn 2.9\% lower revenues than those neighboring ineligible schools. Estimates are larger in magnitude if we focus on the sales of lunch meats (column 3). We expect that CEP adoption disproportionately affects breakfast and lunch food sales because these categories should suffer most acutely if families no longer pack lunch for children under the CEP. Figure 6 shows that this difference in revenues emerges gradually after state adoption of the policy, consistent with the slow take-up of the CEP among eligible schools shown in figure 3. Appendix B.1.1 shows that effects are concentrated among retail outlets located in areas with a higher share of school-age children. Appendix B.1.2 shows that the difference between treatment and control stores is robust to the inclusion of state-by-year FE and eligibility-by-year FEs. As an additional check, Appendix B.1.3 shows that revenues fall more in categories with high family appeal. In Appendix B.1.4, we estimate the effect of the CEP separately by wave of adoption to check for heterogeneous treatment effects.

The results in table 7 further indicate that chain CEP eligibility has no detectable effect on overall store revenue. That is, stores that are not directly exposed to the CEP (their local school is ineligible) do not see a revenue decline overall, even if other retail outlets in the same parent chain are exposed. Taken together, these findings reassure us that chain exposure is not correlated with omitted determinants of grocery demand (conditional on the set of fixed effects in specification 4 .

Table 7: Effect of CEP Exposure on Log Grocery Revenue

\begin{tabular}{lccccccc}
\hline \hline & \multicolumn{3}{c}{ All } & & \multicolumn{3}{c}{$\mathrm{B} / \mathrm{L}$} \\
\cline { 2 - 3 } \cline { 7 - 8 } & $(1)$ & $(2)$ & $(3)$ & & $(4)$ & $(5)$ & $(6)$ \\
\hline State Adopt x Store & $-0.028^{* * *}$ & & $-0.028^{* * *}$ & & $-0.031^{* * *}$ & & $-0.030^{* * *}$ \\
Zip Percent Eligible & $(0.005)$ & & $(0.005)$ & & $(0.005)$ & & $(0.005)$ \\
Chain Average of & & -0.002 & 0.001 & & -0.005 & -0.002 \\
State Adopt x Store Zip Percent Eligible) & & $(0.003)$ & $(0.003)$ & & $(0.003)$ & $(0.003)$ \\
\hline Observations & 53,059 & 53,059 & 53,059 & & 53,059 & 53,059 & 53,059 \\
R-Squared & 0.986 & 0.986 & 0.986 & & 0.985 & 0.985 & 0.985 \\
\hline \hline
\end{tabular}

Notes: All regressions include store and county-year fixed effects. Standard errors are clustered at store level and reported in parentheses $\left({ }^{*} p<0.1,{ }^{* *} p<0.05,{ }^{* * *} p<0.01\right)$. Sales are aggregated to the school year, with sales from September 2014 to August 2015, for example, being associated with CEP participation in the $2014 / 2015$ school year. Chain exposure is normalized. 
Figure 6: Effect of CEP Eligibility Exposure on Log Grocery Revenues

(a) Chain-Level Exposure

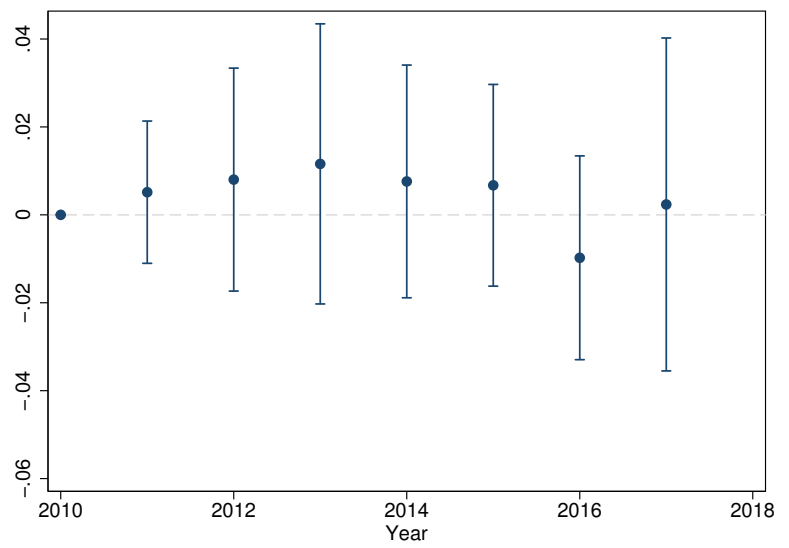

(b) Store-Level Exposure

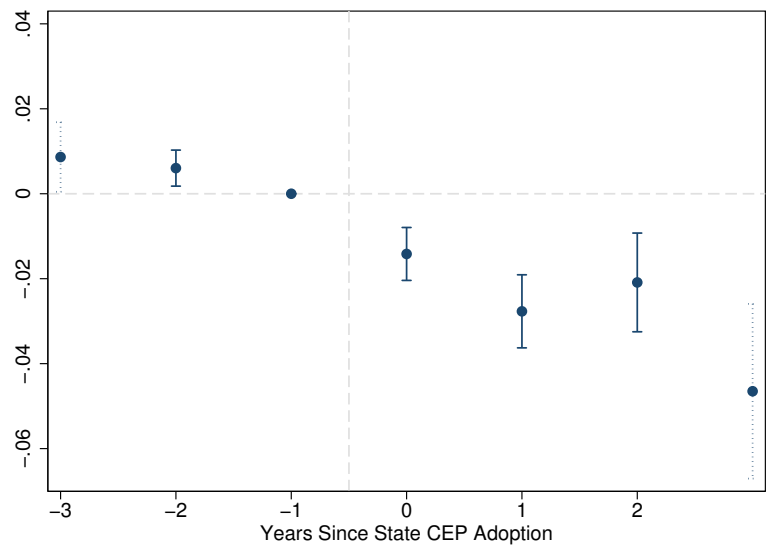

Notes: Plots regression coefficients from specification that includes store and county $\times$ year FE. In addition, plot 6a controls for local eligibility to the CEP and plot $6 \mathrm{p}$ controls for chain exposure. Local CEP eligibility is an enrollment-weighted average of the eligibility of the elementary, middle and high school nearest to the store's ZIP code centroid. Chain exposure is measured as the average of the enrollment-weight average eligibility of schools that neighbor stores in the chain (we normalize this measure for ease of interpretation). The dashed line indicates periods with data for a subset of waves.

\subsection{Extensive Margin Responses}

The reduction in residual demand documented above suggests that the grocery outlets hardest hit by the CEP may exit, and that the CEP may deter entry of new retailers. As a less dramatic form of exit, retailers may eliminate and/or introduce different products in response to the CEP. In this subsection, we directly estimate the effect of the CEP on retailer churn and product assortments.

We adopt specification 4 so that $z$ denotes ZIP code (rather than an individual retail outlet) and the outcome of interest is the number of firms. Note that we include ZIP code and county-by-year fixed effects (but not retailer FE), as in the following equation

$$
\begin{aligned}
\text { NFirms }_{z t} & =\alpha_{0}+\alpha_{1} \cdot 1[\text { StateAdopt }]_{z t}+\alpha_{2} \cdot 1[\text { StateAdopt }]_{z t} \times \text { shareISP } 40_{z} \\
& +\Omega_{z}+\Gamma_{t} \times \Delta_{\text {county }(z)}+\epsilon_{z y} .
\end{aligned}
$$

Table 8 presents estimates of how the CEP affects exits, entries, and the total number of firms for the RMS sample. Note that we exclude instances when an entire chain enters or exits the RMS dataset; our concern is that these entries and exits are a function of the RMS dataset itself, and do not reflect true changes in the local retail environment. We also exclude stores that we cannot match to a school with CEP participation and eligibility data based on the retailer's ZIP code. Unfortunately, the CEP participation data is spotty, so this eliminates about $20 \%$ of the RMS stores. Appendix table 14 displays the sample creation 
criteria.

The results, shown in table 8 column 1, are inconclusive: high-eligibility ZIP codes support slightly fewer Nielsen stores (approximately 1\%) following the adoption of the CEP, but the difference is not statistically significant. The signs of the point estimates indicate a reduction in entries (column 4) and an increase in attrition among existing stores (column 3), but they are also economically small and statistically insignificant. Overall, churn is quite limited in our sample: only 5\% of ZIP codes experience any entry or exit among Nielsen retailers between 2012-2016. This evidence suggests that selection bias is not a concern in our price and revenue regressions (tables 6 and 7 ) because these results consider effects on existing stores. Because entry and exit decisions might operate over a longer time horizon than we study, future work might revisit this margin of retailer response.

Table 8: CEP and Churn among Nielsen Firms

\begin{tabular}{lcccc}
\hline \hline & $(1)$ & $(2)$ & $(3)$ & $(4)$ \\
& N Firms & Change & Exits & Entries \\
\hline State Adopt x Percent Eligible & -0.013 & -0.004 & 0.002 & -0.002 \\
& $(0.015)$ & $(0.009)$ & $(0.008)$ & $(0.005)$ \\
\hline Observations & 23,262 & 23,262 & 23,262 & 23,262 \\
Zip Fixed Effects & Yes & Yes & Yes & Yes \\
R-squared & 0.954 & 0.421 & 0.42 & 0.424 \\
Mean of Dependent Var & 1.445 & -.019 & .035 & .016 \\
\hline \hline
\end{tabular}

Notes: Standard errors in parentheses. ${ }^{*} p<0.1,{ }^{* *} p<0.05,{ }^{* * *} p<0.01$. All regressions include ZIP and county-year fixed effects, are clustered at the ZIP level, and include a constant. The "Percent Eligible" Method assigns each ZIP code a value between 0 and 1 that represents the percent of stores in that ZIP code whose nearest school's ISP is greater than $40 \%$. This is an average of binary values.

Motivated by findings in the SNAP literature (e.g., Jaravel, 2018), we next consider how retailers adjust assortments in response to the CEP. We employ two measures of product assortments: a count of UPCs, and a variety index that weights UPCs by their share of national category sales. The index is meant to capture differences in the appeal and importance of different UPCs following Feenstra (1994) ${ }^{21}$ Results are presented in table 9 and indicate a modest decline in both measures of assortment following the state adoption of the CEP. In contrast to the price and revenue effects we document above, assortments appear to adjust to both local and chain exposure to the CEP. This suggests that there is more local discretion over assortments than prices, but that chain identity still matters, e.g., because contracts with distributors are negotiated at the chain level. While the signs of these estimates are interesting, from a welfare perspective, the magnitudes reported in table

\footnotetext{
${ }^{21}$ Specifically, the variety index calculates the proportion of products (UPCs) sold by store $s$ in month $m$ relative to the total set of products carried across all stores. Each product is weighted by its national sales in month $m$. The final index is calculated as $V_{s, m}=\sum_{u \in U_{s, m}}\left(\frac{v_{u, m}}{\sum_{u \in U_{m}} v_{u, m}}\right)$ where $v_{u, m}$ denotes the national sales of product $u$ in month $m$.
} 
9 are small under typical estimates of substitution elasticities in the literature. For example, a back-of-the-envelope calculation borrowing from Kroft et al. (2021) suggests that a $0.4 \%$ percent reduction in variety reduces welfare by $0.05 \%$.

Table 9: CEP and Product Assortments

\begin{tabular}{|c|c|c|c|}
\hline \multicolumn{4}{|l|}{ Number of UPCs } \\
\hline & (1) & $(2)$ & $(3)$ \\
\hline & All & $\mathrm{B} / \mathrm{L}$ & Lunch Meat \\
\hline State Adopt x Store Zip Percent Eligible & $\begin{array}{c}-0.005^{* * *} \\
(0.002)\end{array}$ & $\begin{array}{c}-0.005^{* * *} \\
(0.002)\end{array}$ & $\begin{array}{c}-0.016^{* * *} \\
(0.003)\end{array}$ \\
\hline Chain Average of (State Adopt x Store Zip Percent Eligible) & $\begin{array}{c}-0.013^{* * *} \\
(0.002)\end{array}$ & $\begin{array}{c}-0.017^{* * *} \\
(0.002)\end{array}$ & $\begin{array}{c}-0.027^{* * *} \\
(0.003)\end{array}$ \\
\hline Observations & 53,059 & 53,059 & 53,059 \\
\hline R-Squared & 0.994 & 0.994 & 0.976 \\
\hline \multicolumn{4}{|l|}{ Variety Index } \\
\hline & (1) & $(2)$ & $(3)$ \\
\hline & All & $\mathrm{B} / \mathrm{L}$ & Lunch Meat \\
\hline State Adopt x Store Zip Percent Eligible & $\begin{array}{c}-0.004^{* * *} \\
(0.001)\end{array}$ & $\begin{array}{c}-0.004^{* * *} \\
(0.002)\end{array}$ & $\begin{array}{c}-0.013^{* * *} \\
(0.005)\end{array}$ \\
\hline Chain Average of (State Adopt x Store Zip Percent Eligible) & $\begin{array}{c}0.002 \\
(0.001)\end{array}$ & $\begin{array}{c}0.002 \\
(0.002)\end{array}$ & $\begin{array}{c}0.007 \\
(0.005)\end{array}$ \\
\hline Observations & 53,059 & 53,059 & 53,059 \\
\hline R-Squared & 0.998 & 0.994 & 0.981 \\
\hline
\end{tabular}

Notes: Outcome variable in the top panel is the log count of UPCs and in the bottom panel is the variety index described above constructed using store-weights. Standard errors in parentheses. ${ }^{*} p<0.1$, ${ }^{* *} p<0.05,{ }^{* * *} p<0.01$. Chain exposure is normalized. All regressions include a constant. Sales are aggregated to the school year, with sales from September 2014 to August 2015, for example, being associated with CEP participation in the 2014/2015 school year.

\subsection{Accounting for Takeup}

Because most eligible schools do not adopt the CEP, we estimate how participation affects stores using instrumental variables to back out the effect of treatment on the treated. To

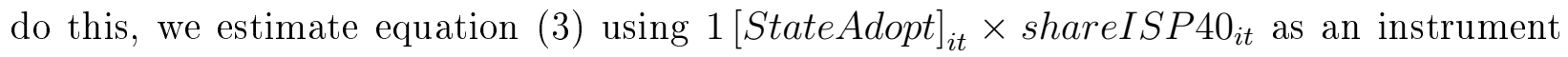
for the share of local schools that participate in the CEP. ${ }^{22}$ This formulation scales the estimator from (4) by take-up in a fashion similar to Hoynes and Schanzenbach (2009). The first stage specification mirrors equation (4), where the dependent variable is the share of schools participating under the CEP (which takes a value between 0 and 1 ). The first stage results are presented in table 10 . They suggest that schools with an ISP above $40 \%$ are around 20 percentage points more likely to adopt the provision than schools in adopting states with ISPs below 40\%. Recall that some schools with low ISPs may qualify for the CEP as part of a larger conglomerate of schools, where the combined ISP is above $40 \%$.

\footnotetext{
${ }^{22}$ Schools that share the same ZIP code as the store.
} 
Despite this possibility, the results indicate large differences in take-up above and below the ISP threshold.

Table 10: First Stage Results

\begin{tabular}{lcccc}
\hline \hline & $(1)$ & $(2)$ & $(3)$ & $(4)$ \\
\hline State Adopt x Percent Eligible & $0.269^{* * *}$ & $0.259^{* * *}$ & $0.248^{* * *}$ & $0.244^{* * *}$ \\
& $(0.008)$ & $(0.007)$ & $(0.007)$ & $(0.008)$ \\
Constant & $0.006^{* * *}$ & $0.003^{* * *}$ & $0.003^{* *}$ & $0.004^{* * *}$ \\
& $(0.001)$ & $(0.001)$ & $(0.001)$ & $(0.001)$ \\
\hline ISP Year & 2009 & 2010 & 2011 & 2012 \\
R-squared & 0.597 & 0.596 & 0.59 & 0.588 \\
Observations & 63,121 & 63,956 & 63,916 & 59,503 \\
\hline \hline
\end{tabular}

Notes: Standard errors in parentheses. ${ }^{*} p<0.1,{ }^{* *} p<0.05,{ }^{* * *} p<0.01$. All regressions include store and county-year fixed effects. Standard errors are clustered at store level.

Underreporting of CEP participation poses a challenge for this IV strategy. Stephens Jr. and Unayama (2019) highlight that underreporting tends to overstate the IV effects, even if underreporting occurs at random (intuitively, the first stage estimate will be too small while the reduced form estimates are unaffected). They show that the IV estimator converges to $\frac{\beta_{1}}{p}$, where $p$ is fraction of schools correctly reporting their CEP status. We estimate $\hat{p} \approx 0.7$ in our setting by comparing the school-level NCES participation rates to aggregate participation rates reported by the Center for Budget and Policy Priorities. To adjust for underreporting, we therefore deflate the IV estimates in table 11 by scaling by $\hat{p}$. The adjusted estimates imply that local CEP adoption reduces grocery revenue for the full calendar year by $9.8 \%$ (column 1), and a one-standard deviation increase in chain exposure reduces prices by $2.45 \%$.

Table 11: Effect of CEP Participation on Grocery Retailers

\begin{tabular}{lccccccc}
\hline \hline & \multicolumn{3}{c}{ Revenue } & & \multicolumn{3}{c}{ Price } \\
\cline { 2 - 3 } \cline { 7 - 8 } & $(1)$ & $(2)$ & $(3)$ & & $(4)$ & $(5)$ & $(6)$ \\
\hline Store Zip CEP & $-0.140^{* * *}$ & & $-0.139^{* * *}$ & & 0.007 & & 0.039 \\
& $(0.023)$ & & $(0.024)$ & & $(0.027)$ & & $(0.027)$ \\
Chain CEP & & -0.003 & 0.001 & & $-0.033^{* * *}$ & $-0.034^{* * *}$ \\
& & $(0.004)$ & $(0.005)$ & & $(0.004)$ & $(0.004)$ \\
\hline First Stage F-Stat & 663 & 1766 & 905 & & 663 & 1766 & 905 \\
Observations & 53,059 & 53,059 & 53,059 & & 53,059 & 53,059 & 53,059 \\
\hline \hline
\end{tabular}

Notes: Standard errors in parentheses. ${ }^{*} p<0.05,{ }^{* *} p<0.01,{ }^{* * *} p<0.001$. All regressions include a control for the years in which the state has adopted the program, and store and county-year fixed effects. Standard errors are clustered at store level. Sales are aggregated to the school year, with sales from September 2014 to August 2015, for example, being associated with CEP participation in the 2014/2015 school year. Chain CEP is standardized. Instrument is the interaction of dummies for state adoption and the nearest school having 40 percent or more eligible for free and reduced lunch in 2010. The first stage is presented in table 10. 
As a benchmark, we compare these estimates to a back-of-the-envelope calculation for the effect of free lunch and breakfast on an average monthly grocery budget, assuming the combined daily cost of lunch and breakfast totaled $\$ 4.15$ before the CEP ${ }^{23}$ Then the CEP amounts to a monthly transfer of approximately $\$ 82.93$ per child, which we use in conjunction with USDA estimates for the cost of food at home to calculate household CEP savings: ${ }^{24}$

$$
\begin{aligned}
\% \Delta \text { Spending } & =\frac{-\# \text { Children } \times \text { Value of Breakfast \& Lunch }}{\text { Monthly Grocery Expenditures for Family of Four }} \\
& =\frac{-2 \times 82.93}{642.10} \times 100 \\
& =-25.83 \%
\end{aligned}
$$

If all Americans were on the "thrifty plan" for the cost of food at home and crowd-out were one-for-one, then we would expect at $25.83 \%$ decline in grocery spending for affected families. The reduction in demand is smaller for the "low-cost plan" (19.60\%). If participation in school meal programs doubles from $40 \%$ to $80 \%$ under the CEP, then store revenue would fall $8 \% .25$ Our estimates are slightly larger, potentially for three reasons: first, lunch spending might constitute a disproportionate share of the grocery bill (if, for example, families eat dinner at restaurants or other on-premise locations); second, fertility rates are higher among lowincome women, so that the household expenditure share of children's food is higher (Monte and Ellis, 2014); and finally, families may substitute to other formats (e.g., dollar stores) and smaller, independent supermarkets for their remaining grocery needs, which is consistent with the household shopping patterns that we present in section 5 .

\section{Welfare Effects of the CEP on Households without School-Aged Children}

In this section, we demonstrate how the chain-level price responses estimated in section 6 propagate spatially, distributing benefits beyond ZIP codes with high local take-up. We estimate a store choice model to measure how local grocery costs adjust in response to CEP adoption from the perspective of households without children-households for whom school lunch provides no direct benefit. We estimate the parameters that govern store choice for these households and hold these parameters fixed to measure the indirect benefit of the CEP.

\subsection{Model Set-up}

A representative household residing in ZIP $o$ allocates its grocery expenditure $w$ across

\footnotetext{
${ }^{23}$ Based on the average price of school meals from the School Nutrition Association's School Meal Trends \& Stats.

${ }^{24}$ Official USDA Food Plans: Cost of Food at Home at Four Levels, U.S. Average, June 2018.

${ }^{25}$ Assume $40 \%$ of households contain no children, but only two adults. Then $\% \Delta$ Revenue $=$ $\frac{0.6 \cdot 0.4 \cdot(-165.86)}{0.4 \cdot 384.5+0.6 \cdot 0.6 \cdot(642.1)+0.6 \cdot 0.4 \cdot(476.24)}$.
} 
the set of stores $s \in S_{t}$ operating at time $t$ to maximize the following CES utility function:

$$
U_{o t}=\left[\sum_{s \in S_{t}} \psi_{o s t}^{\frac{1}{\sigma}} \cdot q_{s t}^{\frac{\sigma-1}{\sigma}}\right]^{\frac{\sigma}{\sigma-1}}
$$

subject to

$$
\sum_{s \in S} p_{s t} \cdot q_{s t} \leq w
$$

where $q_{s t}$ and $p_{s t}$ are consumption and price indexes of store $s$ at time $t ; \psi_{\text {ost }}>0$ is the household's perception of the quality of store $s$ at time $t$; and $\sigma>1$ is the constant elasticity of substitution across stores.

Optimization implies that the representative household allocates a share $s_{\text {ost }}$ of its expenditure to store $s$ as in the following expression:

$$
s_{o s t}=\frac{\psi_{o s t} \cdot p_{s t}^{1-\sigma}}{\sum_{s^{\prime} \in S_{t}} \psi_{o s^{\prime} t} \cdot p_{s^{\prime} t}^{1-\sigma}} .
$$

Substituting this share into utility, we have the standard CES result that indirect grocery utility is equal to retail expenditure $(w)$, divided by a retail price index that summarizes the quality and prices of the stores available to households in origin ZIP $o$ at time $t$ :

$$
P_{o t}=\left(\sum_{s \in S_{t}} \psi_{o s t} \cdot p_{s t}^{1-\sigma}\right)^{\frac{1}{1-\sigma}}
$$

The higher this price index, the more households need to spend to achieve the same grocery utility. The change in grocery utility afforded by a fixed level of expenditure $w$ between two time periods $t_{0}$ and $t_{1}$ is equal to the inverse ratio of this price index between the two periods, $\left(P_{o t_{1}} / P_{o t_{0}}\right)^{-1}$.

We parametrize perceived quality as follows:

$$
\ln \psi_{\text {ost }}=\ln \xi_{\text {os }}+\ln \tilde{\psi}_{\text {ost }}
$$

where $\xi_{o s}$ is the unobserved time-invariant component of utility from origin $o$ at store $s$ and $\tilde{\psi}_{\text {ost }}$ is the unobserved time-varying component of utility from origin $o$ at store $s$ at time $t$, which we assume to be orthogonal to the program. We further parameterize $\xi_{\text {os }}$ as being $\log$ linear in the distance between ZIP $o$ and store $s$ such that $\xi_{o s}=\tilde{\xi}_{o s}-\tau \cdot \ln d_{o s}$. Abstracting 
from the unobservable components of demand, we can re-write the utility index as follows:

$$
\ln \left(\frac{P_{o t_{1}}}{P_{o t_{o}}}\right)=\left(\frac{1}{1-\sigma}\right)\left[\ln \left(\sum_{s \in S_{t_{1}}} d_{o d(s)}^{\tau} \cdot p_{s t_{1}}^{1-\sigma}\right)-\ln \left(\sum_{s \in S_{t_{0}}} d_{o d(s)}^{\tau} \cdot p_{s t_{0}}^{1-\sigma}\right)\right]
$$

This model adds to a growing literature on store choice, including work by Thomasden (2005), Davis (2006), Houde (2012), and Miller and Osborne (2014). Recent work by Ellickson, Grieco, and Khvastunov (2020) employs a model of store choice to explore the effects of grocery mergers. Their model excludes price as a determinant of grocery demand (we note that price is crucial to our objective of measuring the welfare benefits of the CEP price cut), and instead focuses on consumer heterogeneity. Eizenberg, Lach, and Oren-Yiftach (2021) document high travel costs in Jerusalem that sustain price differences across neighborhoods. As in this paper, their model quantifies how shoppers trade off price and distance, using logit demand in place of the CES used here.

\subsection{Estimation}

Equation (8) shows that grocery costs are influenced by two factors: (i) changes in the prices charged by continuing stores $\Delta p_{s t}$ and (ii) changes in the set of stores open $\Delta S_{t}$. The analysis in section 6.4 shows that the CEP had only a small effect on store entry and exit by 2016, so we abstract from changes in the store set and focus on price changes. ${ }^{26}$ We compare realized prices charged by stores operating in 2010 to counterfactual price indexes based on the estimated impact of the CEP.

Specifically, we calculate:

$$
\ln \left(\frac{P_{\hat{o t}_{1}}}{P_{o t_{o}}}\right)=\left(\frac{1}{1-\sigma}\right)\left[\ln \left(\sum_{s \in S_{t_{0}}} d_{o d(s)}^{\tau} \cdot\left(p_{s t_{0}}+\widehat{\Delta p_{s}}\right)^{1-\sigma}\right)-\ln \left(\sum_{s \in S_{t_{0}}} d_{o d(s)}^{\tau} \cdot p_{s t_{0}}^{1-\sigma}\right)\right](9)
$$

where $\widehat{\Delta p_{s}}$ is the estimated impact of the CEP on the price level charged by store $s$ as a function of its ZIP code $d(s)$ and chain $c(s)$. We predict this impact using the price results in column 3 of Table 11; that is, $\widehat{\Delta p_{s}}=\hat{\beta}_{1} \cdot C E P_{d(s) 2016}+\hat{\beta}_{2} \cdot C h a i n C E P_{c(s) 2016}+\hat{\beta}_{3} \cdot C E P_{d(s) 2016}$. ChainCEP $P_{c(s) 2016}$.

In the model, the impact of a price adjustment at a store $s$ on grocery costs in an origin ZIP code $o$ depends on the distance of that ZIP code from the store ZIP code, $d_{o d(s)}$, mediated by the distance elasticity $\tau$ and the elasticity of substitution between stores $\sigma$. We proxy for $d_{o d}$ with the distance between the centroid of ZIP code $o$ to the centroid of ZIP code $d$ when $o \neq d$ and the mean distance from two points in a circle with the same area as ZIP code $o$

\footnotetext{
${ }^{26}$ The model can be adjusted to account for extensive margin responses to the CEP, both at the store-level and the productlevel within stores.
} 
when $o=d$. We use 2010, the year before the CEP's inception, as the initial period $t_{0}$, and 2016 , the last year that we have price data for, as our final year $t_{1}$.

We estimate the key demand parameters $\sigma$ and $\tau$ using maximum likelihood. Interpreting the right-hand side of equation (6) as a probability and denoting the number of individuals residing in origin ZIP code $o$ and shopping at store $s$ in academic year $t$ as $\ell_{\text {ont }}$, the $\log$ likelihood function is

$$
\ln \mathcal{L}=\sum_{o s t} \ell_{o s t} \ln \left[\frac{\psi_{o s t} \cdot p_{s t}^{1-\sigma}}{\sum_{s^{\prime} \in S_{t}} \psi_{o s^{\prime} t} \cdot p_{s^{\prime} t}^{1-\sigma}}\right]=\sum_{o s t} \ell_{o s t} \ln \left[\frac{d_{o d(s)}^{\tau} \cdot \tilde{\psi}_{o s t} \cdot p_{s t}^{1-\sigma}}{\sum_{s^{\prime} \in S_{t}} d_{o d\left(s^{\prime}\right)}^{\tau} \cdot \tilde{\psi}_{o s^{\prime} t} \cdot p_{s^{\prime} t}^{1-\sigma}}\right]
$$

where, in the second equality, perceived destination quality is parameterized as in equation (7).

Estimation proceeds using a Poisson pseudo-maximum-likelihood estimator (PPMLE) where price indexes are calculated from annual store-level data and expenditures are taken from HMS data on the purchases that adult-only households residing in each ZIP code make in each destination store. This estimator relies on the assumption that time-varying origin-store match quality is mean-independent from distance and store prices, conditional on controls $\xi_{\text {ost }}$; that is, $\mathbb{E}\left(\tilde{\psi}_{\text {ost }} \mid d_{o d(s)}, p_{\text {st }}, \xi_{\text {ost }}\right)=1$ (Silva and Tenreyro, 2006). In our baseline specification, $\xi_{\text {ost }}$ includes origin ZIP-by-year, destination store chain, and destination store ZIP fixed effects.

To address attenuation and endogeneity biases that might affect our $\sigma$ estimate, we instrument for store prices with (i) the sales-weighted average of the log price level charged by stores

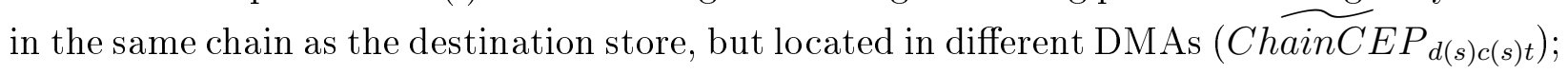
(ii) the sales-weighted average of the log price level charged by stores in the same chain as those in the origin ZIP code, but located in different DMAs $\left(\widetilde{C h a i n C E} P_{d\left(s_{o}\right) c\left(s_{o}\right) t}\right)$; and (iii)

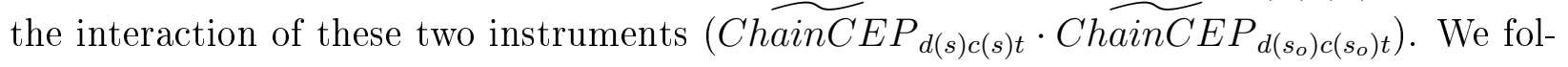
low the control function approach proposed by Lin and Wooldridge (2019), bootstrapping the procedure to obtain consistent standard errors.

This specification yields our preferred estimate for the elasticity of substitution $(\sigma)$ of 2.8 and distance elasticity $(\tau)$ of -2.4 . Because stores enter endogenously in response to nearby demand, we test the robustness of these estimates to additional controls for the unobserved quality component of the error term $\left(\tilde{\psi}_{\text {ost }}\right)$. The distance elasticity is robust to these controls. The substitution elasticity increases to 3.5 when the store chain fixed effects are dropped, but this difference is not statistically significant and our results below are almost entirely invariant to this adjustment given the spatial correlation in store-level price changes. 
Table 12: Store Choice Elasticities

\begin{tabular}{lcccc}
\hline \hline & $(1)$ & $(2)$ & $(3)$ & $(4)$ \\
\hline Log Price & 0.192 & & & -2.573 \\
& $(0.162)$ & & & $(1.472)$ \\
Log Distance & $-2.417^{* * *}$ & $-2.418^{* * *}$ & $-0.000^{* *}$ & $-2.425^{* * *}$ \\
& $(0.024)$ & $(0.024)$ & $(0.000)$ & $(0.047)$ \\
Log Store Chain Price & & $-2.511^{* * *}$ & $1.131^{* * *}$ & \\
& & $(0.675)$ & $(0.025)$ & \\
\hline Model & OLS & RF & FS & 2-Step IV \\
Origin Zip-Store Zip Standard Error Clustering & Yes & Yes & Yes & Yes \\
F-Statistic & & & 1067 & \\
Pseudo R-Squared & 0.712 & 0.712 & 0.748 & 0.712 \\
Observations & 396,687 & 396,687 & 396,687 & 396,687 \\
\hline \hline
\end{tabular}

Notes: Standard errors, clustered by ZIP pair, in parentheses. ${ }^{*} p<0.1,{ }^{* *} p<0.05,{ }^{* * *} p<0.01$. All regressions include a constant. Includes ZIP*year, destination chain, and destination ZIP fixed effects.

\subsection{Welfare Results}

We recover the welfare impact of the CEP in each origin ZIP code by plugging the estimates for the impact of the policy on store prices $\left(\widehat{\Delta p_{s}}\right)$ and elasticities $(\hat{\sigma}$ and $\hat{\tau})$ obtained above into equation (9). Welfare is measured as the change in grocery costs, inclusive of travel costs and product prices. The population-weighted distribution of these welfare estimates is presented in Figure 7. The median effect is a decrease in grocery costs of approximately 4.5 percentage points. This reduction amounts to an $\$ 9$ monthly benefit, given the average monthly grocery expenditure from table 2 , which is approximately $10 \%$ of the $\$ 80$ direct monthly benefit to each child receiving free school meals. ${ }^{27}$

There is a significant degree of variation across ZIP codes. Part of this variation can be explained by the spatial distribution of CEP take-up, and the spatial distribution of chains with differential exposure to areas where the CEP is adopted.

Figure 8 illustrates this variation using the Chicago area as a case study. Panel a shows the share of stores in each ZIP code whose closest school participated in the CEP program in 2016. Panel b shows the average CEP exposure of the chains that operate stores in the ZIP code. Direct exposure is spatially concentrated, but the indirect impact of the program extends beyond these communities to other ZIP code, particularly along the Indiana-Illinois border.

Figure 9 shows the correlation between the indirect benefits of the program and proximity to ZIP codes with different levels of direct and indirect exposure to the CEP program,

\footnotetext{
${ }^{27}$ Based on the average price of school lunch and breakfast from the School Nutrition Association's School Meal Trends \& Stats.
} 
measured as the weighted average of direct and indirect exposure using the distance weights $\left(d_{o d}^{\tau}\right)$. ZIP codes with higher indirect CEP exposure see much larger reductions in grocery costs. In fact, most of the cross-ZIP variation in the estimated welfare impact of the program is explained by variation in the indirect exposure to the program via which chains operate in the vicinity of different ZIP codes. ZIP codes with high densities of heavily exposed chains, which are predicted to reduce their prices in response to the program, saw grocery costs fall by up to 10 percentage points, while ZIPs with low-exposure chains saw grocery costs fall by only 3 percentage points. Figure 8 shows that the largest welfare benefits were in ZIPs with zero direct effects and strong indirect effects.

Figure 7: Effects of the CEP on Grocery Costs between 2000 and 2016

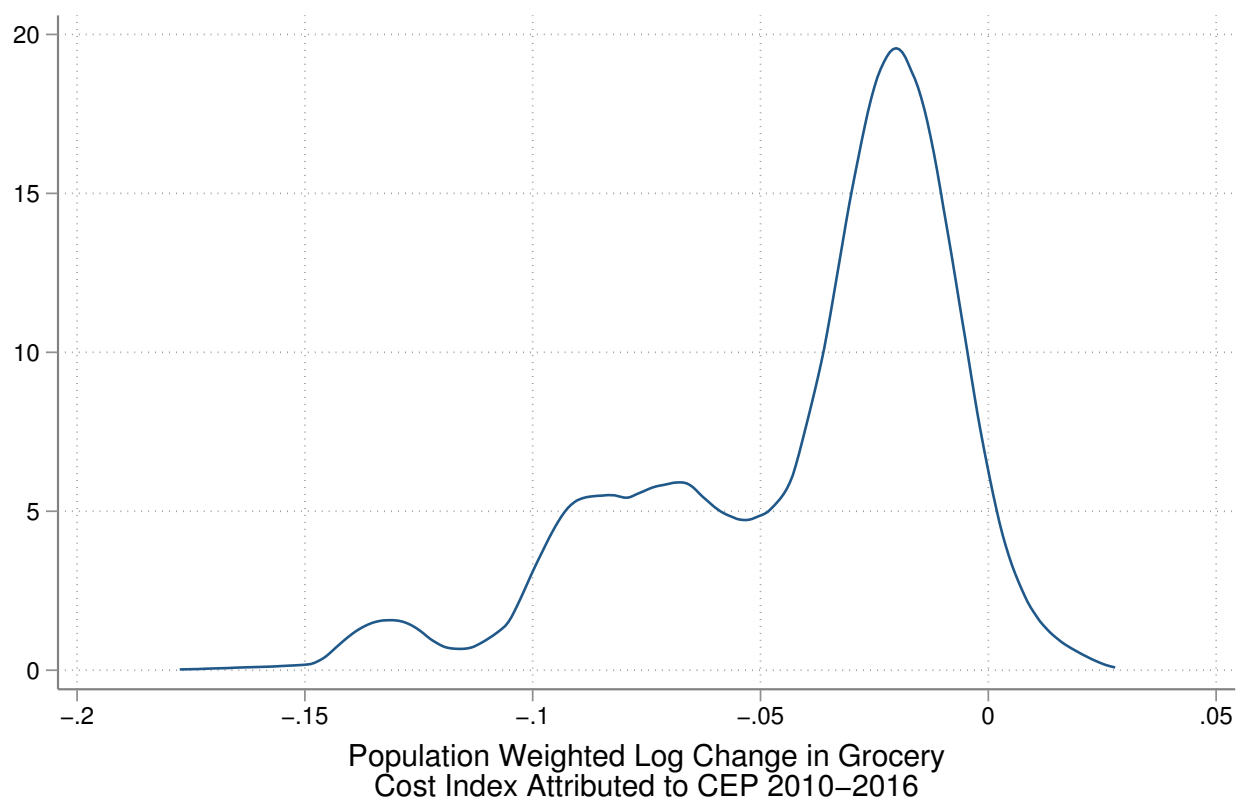

Notes: This figure plots the distribution of CEP effects across ZIP codes. For each ZIP code, we calculate the log change in its grocery cost index caused by the CEP. The magnitude of the effect depends on the exposure of the retail chains located in the ZIP code. 
Figure 8: Direct and Indirect Exposure to CEP Program in 2016, Chicago

(a) Direct Exposure

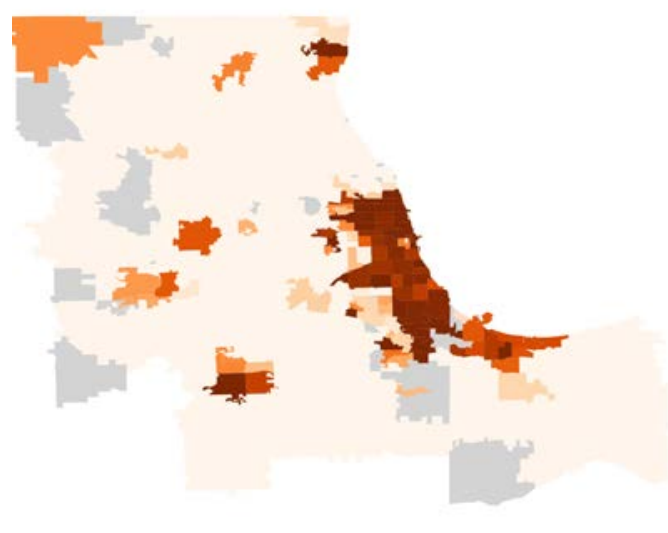

(b) Indirect Exposure

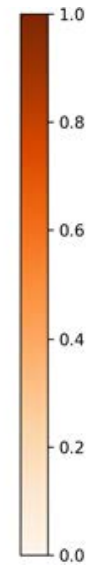

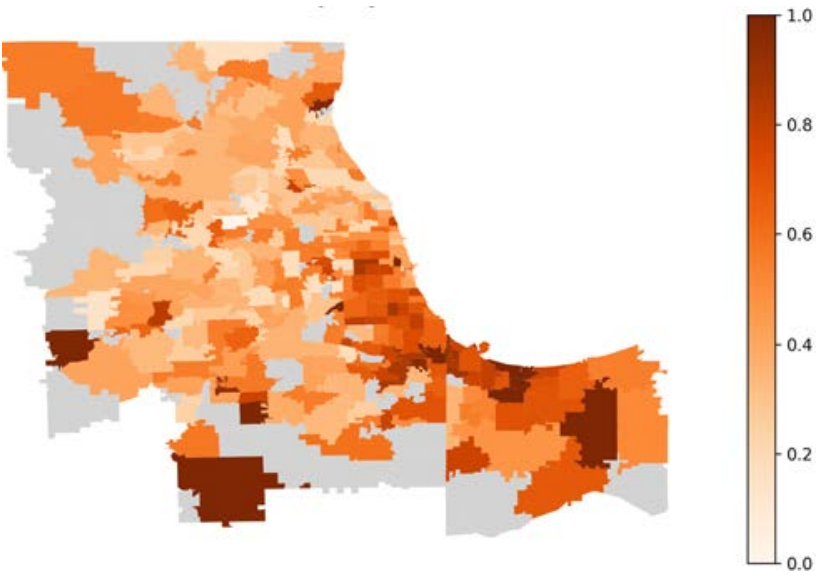

Notes: Panel a plots direct exposure to the CEP in each ZIP code in the Chicago area in 2016. Direct exposure in a ZIP code is the enrollment-weighted average eligibility of the elementary, middle, and high school nearest the ZIP code centroid. Panel b plots indirect exposure to the program, which is measured as the average CEP exposure of retail grocery chains that operate in the focal ZIP code, excluding the exposure in the focal ZIP code.

Figure 9: The Effect of Direct and Indirect Exposure to the CEP on Grocery Costs

(a) Direct Exposure

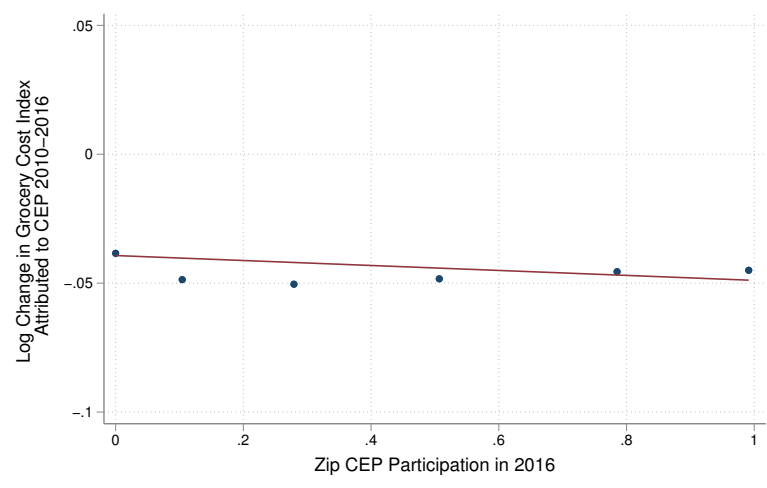

sigma $=2.4$ (b) Indirect Exposure

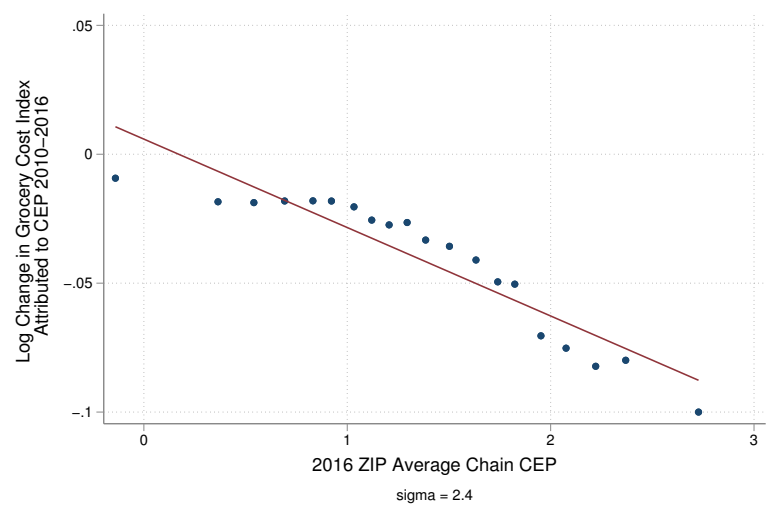

Notes: The binned scatterplot in panel a shows the relationship between direct exposure to the CEP and the log change in grocery costs attributable to the CEP. The binned scatterplot in panel b shows the relationship of CEP benefits with indirect exposure. Grocery cost changes are calculated based on our estimates of $\sigma=2.8$ and $\tau=-2.4$ from Table 12 . 
Figure 10: Heat Map of Effect of the CEP on Grocery Costs between 2000 and 2016

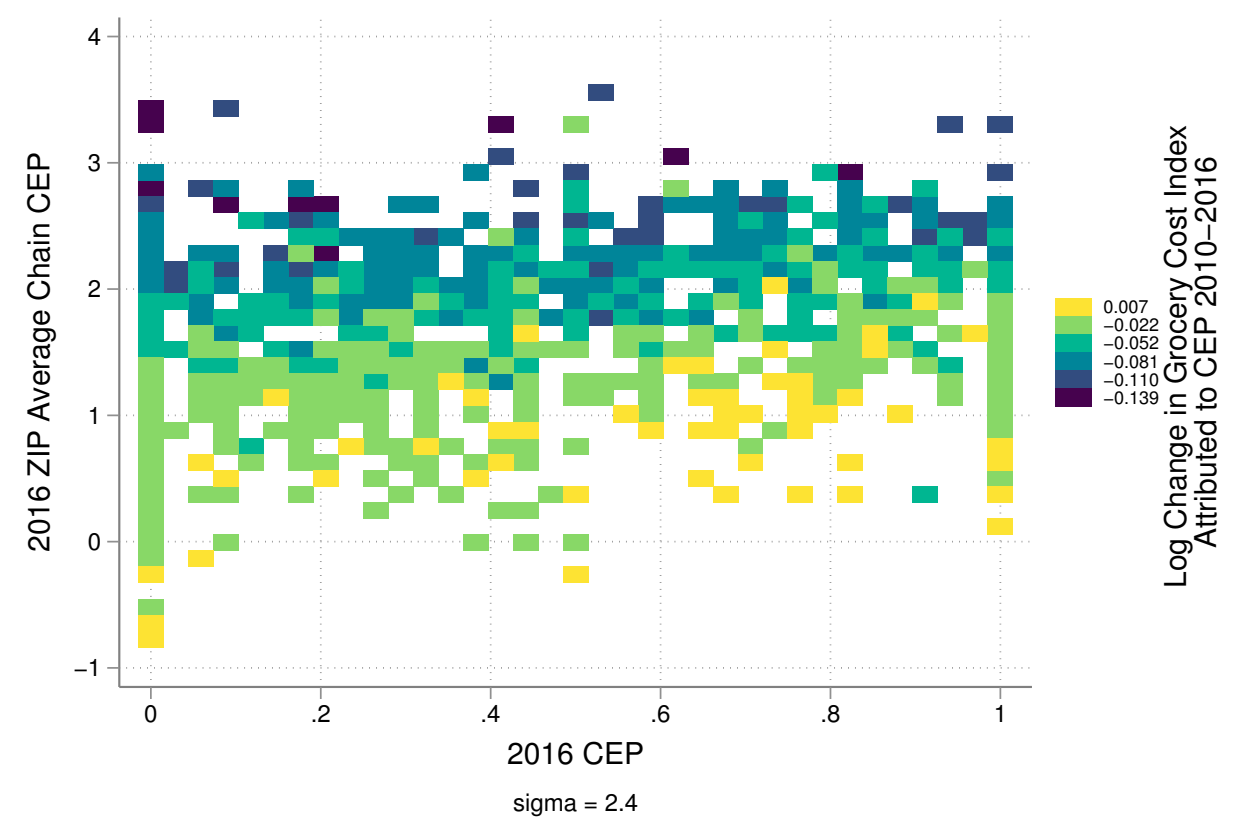

Notes: This figure plots the relationship between local CEP participation in 2016, chain exposure to the CEP in 2016, and the change in grocery costs attributable to the CEP. Grocery costs decline mostly steeply in ZIP codes with high chain exposure.

The model above allows us to also calculate the change in ZIP-level shopping costs that result from all changes in store prices (rather than just the changes attributable to the CEP). Figure 11 is a binscatter showing the association between the change in the grocery cost index attributable to the CEP and the total change in the grocery cost index. The $\mathrm{x}$-axis shows that overall grocery price inflation in continuing stores between 2010 and 2016 has resulted in grocery costs increasing in almost all ZIP codes, with most ZIP codes seeing 10 to 30 percent increases in grocery costs. Our analysis suggests that the CEP program counteracted these general trends, mitigating price increases observed in the data over the same period. Figure 11 shows that the CEP program helps to explain some of the spatial variation in price declines: ZIPs with larger predicted spillovers from CEP to shopping costs tended to see smaller increases in their aggregate grocery cost growth. 
Figure 11: Welfare Effects of the CEP Relative to Overall Changes in Shopping Costs

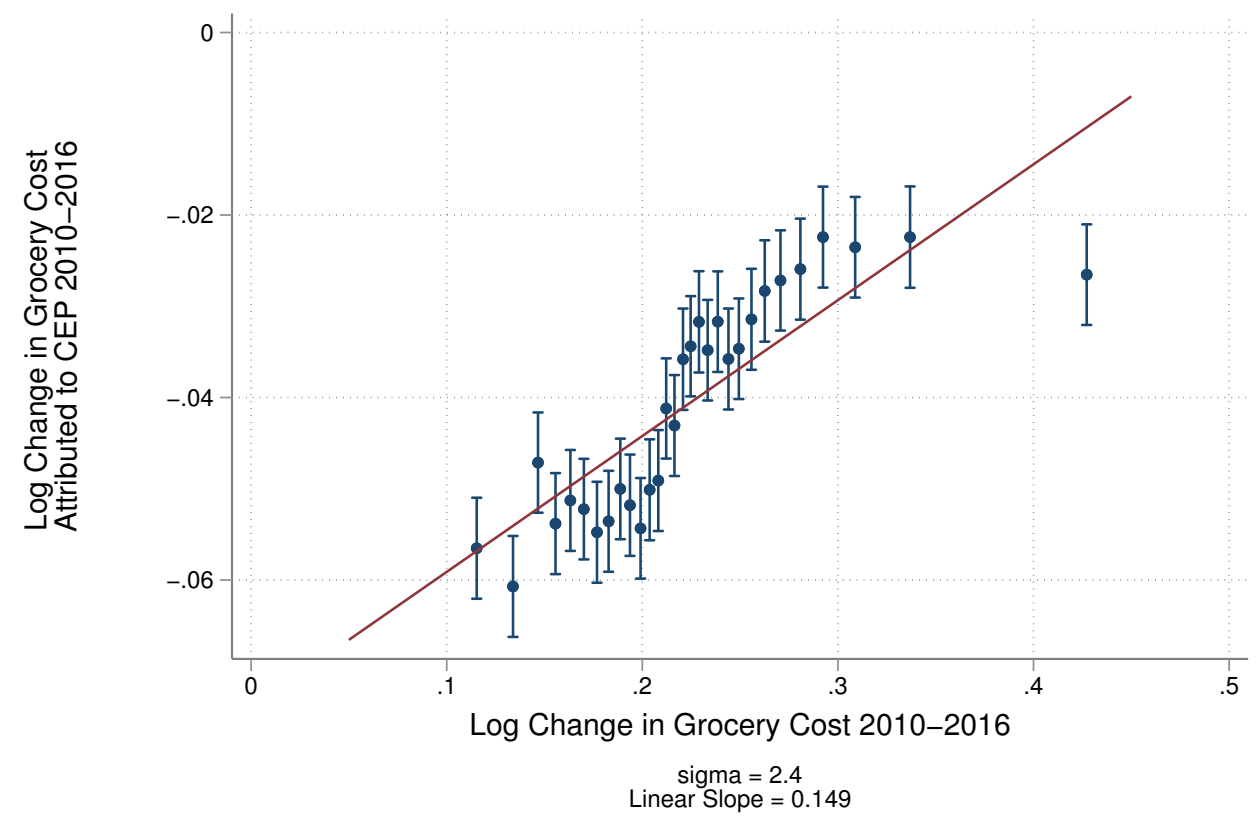

Notes: This plot shows the relationship between observed changes in grocery costs across ZIP code from 2010-2016 and the estimated changes in grocery costs attributed to the CEP. The CEP has counteracted a general trend in rising grocery costs.

\section{Conclusion}

This paper demonstrates that the National School Lunch Program delivers a substantial indirect benefit to communities through its supply-side effects. To establish causality, we leverage an expansion of the NSLP under the Community Eligibility Provision, which requires that participating schools provide free lunch to all students, in essence, lowering the price of a substitute for grocery store lunch products. Panel data on household grocery purchases reveal that households with children reduce their spending by $7 \%$ when a local school adopts the CEP. We then show that grocery stores respond to this demand shock by reducing prices.

To quantify the benefit of the program to adult-only households, we estimate a CES model of grocery demand. The welfare estimates suggest that the CEP reduces shopping costs in the median effected ZIP code on the order of $4.5 \%$ by 2016 . For comparison, a back-of-the-envelope calculation suggests that the annual direct benefit of the NSLP for a household with children amounts to a $25 \%$ reduction in shopping costs.

A final finding is that the spatial distribution of retail grocery chains determines the distribution of the indirect benefits. Chain geography is important because many retail grocery chains in the US employ uniform pricing. Accordingly, we find that retailers do 
not adjust prices in response to local CEP adoption; rather, retail chains adjust prices in response to their overall exposure across outlets. Consequently, some consumers enjoy lower prices even when their local school does not adopt the program. Taken together, our findings show that supply-side forces can meaningfully amplify the benefits of food security policy.

\section{References}

Brian Adams and Kevin R. Williams. Zone pricing in regional oligopoly. American Economic Journal: Microeconomics, 11(1):124-156, 2019.

David Atkin, Benjamin Faber, and Marco Gonzalez-Navarro. Retail globalization and household welfare: Evidence from mexico. Journal of Political Economy, 126(1):1-73, 2018.

Martin Beraja, Erik Hurst, and Juan Ospina. The aggregate implications of regional business cycles. Econometrica, 87(6):1789-1833, 2019.

Janet Bhattacharya, Jayanta annd Currie and Steven J. Haider. Breakfast of champions? the school breakfast program and the nutrition of children and families. Journal of Human Resources, 41(3):445-466, 2006.

Jeremy Bulow, John Geanakoplos, and Paul Klemper. Multimarket oligopoly: Strategic substitutes and complements. Journal of Political Economy, 93(3):488-511, 1985.

Sebastian Calonico, Matias D Cattaneo, Max H Farrell, and Rocio Titiunik. rdrobust: Software for rregression discontinuity designs. The Stata Journal, 17(2):372-404, 2017.

Doruk Cengiz, Arindrajit Dube, Attila Lindner, and Ben Zipperer. The effect of minimum wages on low-wage jobs. Quarterly Journal of Economics, 134(3):1405-1454, 2019.

Jesse M. Cunha, Giacomo De Giorgi, and Seema Jayachandran. The price effects of cash versus in-kind transfers. The Review of Economic Studies, 86(1):240-281, 2018.

Peter Davis. Spatial competition in retail markets: Movie theaters. The RAND Journal of Economics, 37(4):964-982, 2006.

Stefano DellaVigna and Matthew Gentzkow. Uniform pricing in u.s. retail chains. Quarterly Journal of Economics, 134(4):2011-2084, 2019.

Alon Eizenberg, Saul Lach, and Merav Oren-Yiftach. Retail prices in a city. American Economic Journal: Economic Policy, 13(2):175-206, 2021.

Paul B. Ellickson, Paul L. Grieco, and Oleksii Khvastunov. Measuring competition in spatial retail. The RAND Journal of Economics, 51(1):189-232, 2020. 
Robert C. Feenstra. New product varieties and the measurement of international prices. The American Economic Review, 84(1):157-177, 1994.

Deon Filmer, Jed Friedman, Eeshani Kandpal, and Junko Onishi. Cash transfers, food prices, and nutrition impacts on ineligible children. The Review of Economics and Statistics, pages 1-45, May 2021.

Richard G. Frank and David S. Salkever. Pricing, patent loss and the market for pharmaceuticals. Southern Economic Journal, 59(2):165-179, 1992.

David E. Frisvold. Nutrition and cognitive achievement: An evaluation of the school breakfast program. Journal of Public Economics, 124:91-104, 2015.

Ezequiel García-Lembergman. Multi-establishment firms, pricing and the propagation of local shocks: Evidence from U.S. retail. Working Paper, 2020.

Andrew Goodman-Bacon. Difference-in-differences with variation in treatment timing. Journal of Econometrics, 2021.

Nora Gordon and Krista Ruffini. Schoolwide free meals and student discipline: Effects of the Community Eligibility Provision. Education Finance and Policy, 2021.

Justine Hastings and Ebonya Washington. The first of the month effect: Consumer behavior and store responses. American Economic Journal: Economic Policy, 2(2):142-162, May 2010 .

Guenter Hitsch, Ali Hortacsu, and Xiliang Lin. Prices and promotions in U.S. retail markets: Evidence from big data. Working Paper, 2019.

Jean-Francois Houde. Spatial differentiation and vertical mergers in retail markets for gasoline. American Economic Review, 102(5):2147-2182, 2012.

Hilary W. Hoynes and Diane Whitmore Schanzenbach. Consumption responses to in-kind transfers: Evidence from the introduction of the food stamp program. American Economic Journal: Applied Economics, 1(4):109-139, 2009.

Xavier Jaravel. What is the impact of food stamps on prices and product variety? the importance of the supply response. AEA Papers and Proceedings, 108:557-561, 2018.

Kory Kroft, Jean-Williams Laliberté, René Vizcaino, and Matthew J. Notowidigdo. A welfare analysis of tax structures with love-of-variety preferences. Working Paper, 2021.

Justin Leung and Hee Kwon Seo. How do government transfer payments affect retail prices and welfare? evidence from SNAP. Working Paper, 2018. 
Wei Lin and Jeffrey $M$ Wooldridge. Testing and correcting for endogeneity in nonlinear unobserved effects models. In Panel Data Econometrics, pages 21-43. Elsevier, 2019.

Justin McCrary. Manipulation of the running variable in the regression discontinuity desiggn: A density test. Journal of Econometrics, 142:698-714, 2008.

Nathan H. Miller and Mathew Osborne. Spatial differentiation and price discrimination in the cement industry: Evidence from a structural model. The RAND Journal of Economics, $45(2): 221-247,2014$.

Robert Moffitt. An economic model of welfare stigma. The American Economic Review, 73 (5):1023-1035, December 1983.

Lindsay M. Monte and Renee R. Ellis. Fertility of women in the United States: 2012. Technical report, US Census Bureau, Economics and Statistics Administration, July 2014.

Zhuan Pei and Yi Shen. The devil is in the tails: Regression discontinuity design with measurement error in the assignment variable. In Advances in Econometrics, volume 38, pages 455-502. Emerald Publishing Limited, 2017.

Krista Ruffini. Universal access to free school meals and student achievement: Evidence from the community eligibility provision. Journal of Human Resources, Forthcoming.

Diane Schanzenbach. Do school lunches contribute to childhood obesity? Journal of Human Resources, 44(3):684-709, 2009.

Diane Schanzenbach and Mary Zaki. Expanding the school breakfast program: Impacts on children's consumption, nutrition and health. NBER Working Paper, (w20308), 2014.

Amy Ellen Schwartz and Michah W. Rothbart. Let them eat lunch: The impact of universal free meals on student performance. Journal of Policy Analysis and Management, 39(2): 376-410, 2020.

Becca Segal, Jessie Hewins, Mieka Sanderson, Catlin Nchako, Zoë Neuberger, Lexin Cai, and Alison Maurice. Community eligibility adoption rises for the 2015-2016 school year, increasing access to school meals. Food Research and Action Center. http://frac. org/wpcontent/uploads/take-up-of-cep-report. pdf May, 13, 2016.

JMC Santos Silva and Silvana Tenreyro. The log of gravity. The Review of Economics and Statistics, 88(4):641-658, 2006.

Melvin Stephens Jr. and Takashi Unayama. Estimating the impacts of program benefits: Using instrumental variables with underreported and imputed data. The Review of Economics and Statistics, 101(3):468-475, 2019. 
Johannes Stroebel and Joseph Vavra. House prices, local demand, and retail prices. Journal of Political Economy, 127(3):1391-1436, 2019.

Liyang Sun and Sarah Abraham. Estimating dynamic treatment effects in event studies with heterogeneous treatment effects. Journal of Econometrics, Forthcoming.

Raphael Thomasden. The effect of ownership structure on prices in geographically differentiated industries. The RAND Journal of Economics, 36(4):908-929, 2005. 


\section{A Data Appendix: Tables \& Figures}

Table 13: Breakfast and Lunch Food Categories

\begin{tabular}{|l||l|}
\hline BAKED GOODS-FROZEN & EGGS \\
\hline \hline BAKING MIXES & FRESH PRODUCE \\
\hline \hline BAKING SUPPLIES & FRUIT - DRIED \\
\hline \hline BREAD AND BAKED GOODS & JAMS, JELLIES, SPREADS \\
\hline \hline BREAKFAST FOOD & JUICE, DRINKS - CANNED, BOTTLED \\
\hline \hline BREAKFAST FOODS-FROZEN & MILK \\
\hline \hline BUTTER AND MARGARINE & NUTS \\
\hline \hline CEREAL & PACKAGED MEATS-DELI \\
\hline \hline CHEESE & PREPARED FOOD-READY-TO-SERVE \\
\hline \hline CONDIMENTS, GRAVIES, AND SAUCES & SALAD DRESSINGS, MAYO, TOPPINGS \\
\hline \hline COOKIES & SNACKS \\
\hline \hline COT CHEESE, SOUR CREAM, TOPPINGS & SNACKS, SPREADS, DIPS-DAIRY \\
\hline \hline CRACKERS & SOFT DRINKS-NON-CARBONATED \\
\hline \hline DESSERTS, GELATINS, SYRUP & TABLE SYRUPS, MOLASSES \\
\hline \hline DOUGH PRODUCTS & UNPREP MEAT/POULTRY/SEAFOOD-FRZN \\
\hline \hline DRESSINGS/SALADS/PREP FOODS-DELI & YOGURT \\
\hline
\end{tabular}

Notes: This table reports the product modules that we categorize as breakfast and lunch products.

Figure 12: Chain Exposure to the CEP over Time

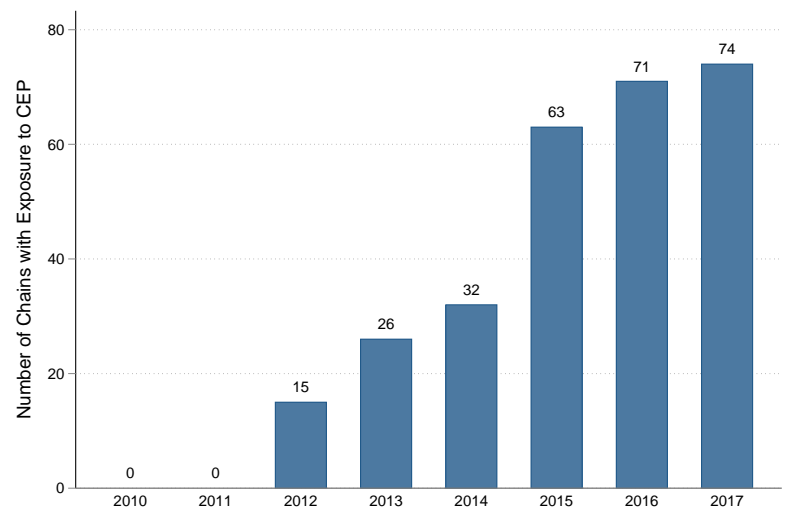

Notes: This figure plots exposure to the Community Eligibility across retail grocery chains in the Nielsen RMS dataset. The program began in 2012, so exposure is zero in 2010 and 2011. Exposure grows dramatically in 2015 when all states adopt the program. Table 1 provides the timing of adoption across states. 
Table 14: Sample Construction for Store Attrition Analysis

\begin{tabular}{llc}
\hline Initial Pool $=9,929$ & & \\
\hline Criterion: & & \\
\cline { 2 - 3 } 1. & Unbalanced RMS Panel & 171 \\
2. & Entire chain entry/exit from RMS & 1,489 \\
3. & Store switches chain affiliation & 77 \\
4. & No school match with 2010 ISP \& Participation Data & 1,632 \\
\hline Final Sample $=6,808$ & & \\
\hline
\end{tabular}

Notes: This table describes the criteria that we use to create the sample of Nielsen RMS stores for our analysis of store exits in section 6.4. Most retail outlets are dropped if the entire chain exits or enters the RMS data so that we cannot observe changes in the outlet's survival or if we cannot match the retail outlet to CEP exposure.

Table 15: Match Rate between NCES and State DOE Data

\begin{tabular}{lcccc}
\hline \hline State & NCES and State CEP & NCES Only & State CEP Only & Total \\
\hline $\begin{array}{l}\text { District of } \\
\text { Columbia }\end{array}$ & 80 & 144 & 0 & 224 \\
Illinois & 508 & 7907 & 139 & 8554 \\
Kentucky & 440 & 2373 & 42 & 2855 \\
Michigan & 827 & 6218 & 144 & 7189 \\
Ohio & 4 & 3625 & 0 & 3629 \\
$\begin{array}{l}\text { West } \\
\text { Virginia }\end{array}$ & 249 & 505 & 34 & 788 \\
Total & 2108 & 20772 & 359 & 23239 \\
\hline \hline
\end{tabular}

Notes: This table compares CEP participation data from the National Center for Education Statistics and the State Departments of Education. We collect this data for early-adopting states only. 
Figure 13: CEP Adoption Rates over Time:

School CEP Adoption Share By Year of Adoption

(a) Year 1

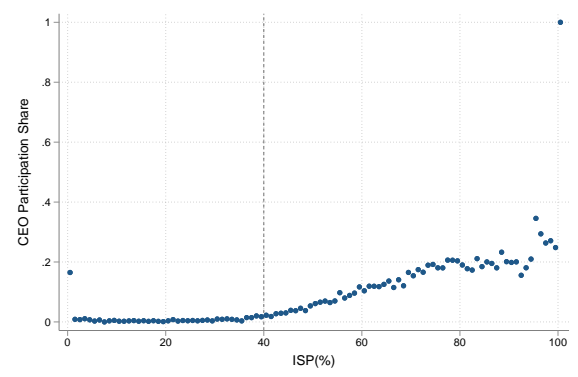

(c) Year 3

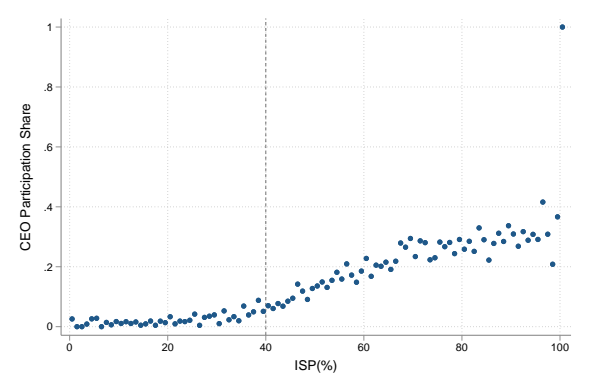

(b) Year 2

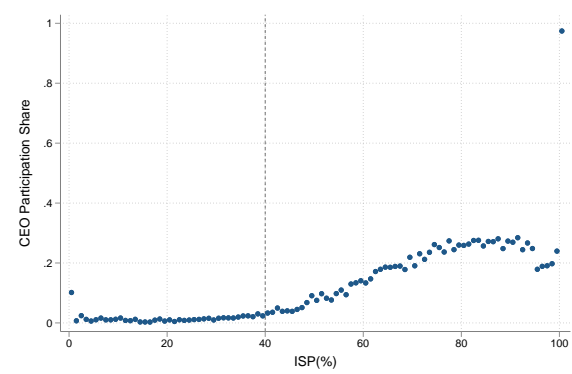

(d) Year 4

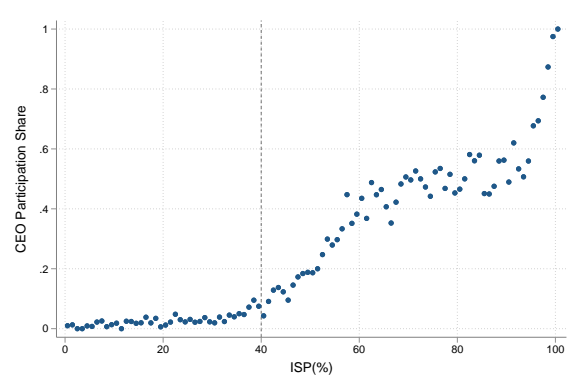

Notes: This figure plots school participation rates in the CEP by ISP and years since state adoption. Table 1 provides information on the timing of state CEP adoption. 


\section{B Robustness}

\section{B.1 Evidence on Lunches Served}

An explicit goal of the CEP is to increase the number of students that eat school lunch. If the program is successful, then fewer families ought to buy ingredients at supermarkets to send with children as home-packed lunches. Thus, we estimate the effect of the CEP on lunches served in schools as additional evidence that the CEP affects demand for groceries. However, we note that CEP spillovers may be large event absent an increase in school lunches served. In equilibrium, competitors might respond to the CEP so as to maintain market share, for example, by lowering prices.

Table 16: Summary Statistics on Participation and Eligibility for Wisconsin Schools

\begin{tabular}{lcccc}
\hline \hline & $(1)$ & $(2)$ & $(3)$ & $(4)$ \\
& District CEP & LEA CEP & Non Part & School CEP \\
\hline School ISP & 0.682 & 0.679 & 0.219 & 0.545 \\
District ISP & 0.622 & 0.556 & 0.216 & 0.329 \\
ADP & 0.769 & 0.717 & 0.534 & 0.748 \\
\hline Observations & 24 & 255 & 1749 & 24 \\
\hline \hline
\end{tabular}

Notes: This table presents summary statistics broken out by whether/how a school participates in the CEP. For example, the sample in column 1 is the set of schools that participate in the CEP with their entire district, so that the district's ISP is the basis for qualification. Data is from Wisconsin AY 2017-2018. ADP is the Average Daily Participation rate for school lunch. The ISP cutoff is 0.4 for individual school eligibility into the CEP.

We investigate substitution patterns using school-level adoption data from Wisconsin in the 2017-2018 academic year. For each school, the Wisconsin Department of Education provided us information on ISP, ${ }^{28} \mathrm{CEP}$ participation, and ADP, average daily participation rate in school lunch. Table 16 provides summary statistics for this sample, broken out by CEP status. Schools participating under the CEP have higher average daily participation rates, which is consistent with a positive impact of the program. However, these schools also have higher ISPs than those that do not participate, which could drive the pattern in ADP even absent an effect of the program. Most schools participate in the CEP as part of a Local Education Agency (LEA), which describes any group of two or more schools in the same district. However, twenty-four schools choose to participate individually, which means that their individual ISP must exceed the $40 \%$ threshold. We leverage these schools to estimate

\footnotetext{
${ }^{28}$ The data from Wisconsin includes the true ISP, which governs eligibility for the CEP. Throughout the rest of the paper, we use the percent of free lunch eligible students as a proxy for ISP.
} 
the causal effect of the CEP on ADP using a regression discontinuity design (RDD), following the methods outlined in Calonico et al. (2017). One concern is that schools may adjust their ISPs in order to qualify for the program; indeed, in section 4 we present evidence of bunching using a national sample of schools. In figure 14, we test for a discontinuity in the density of Wisconsin schools around 40\%, but find no evidence of a bunching. We note that while the smoothness of the pdf is reassuring, the fundamental identification assumption that schools do not game ISP in Wisconsin is untestable.

Figure 14: RDDensity Plot: Wisconsin Data

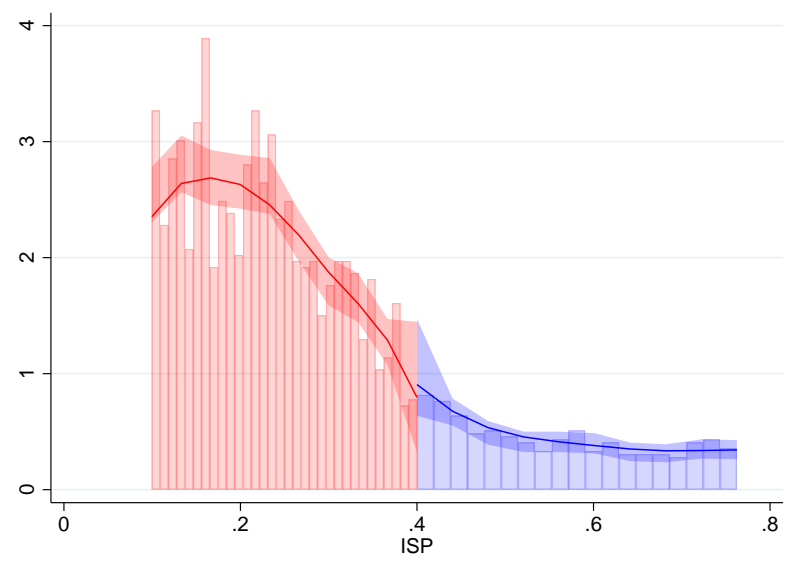

Notes: This figure plots a kernel-smoothed density of ISP rates for Wisconsin schools in the 2017/2018 AY.

We estimate the effect of the CEP on ADP using the following model:

$$
y_{i}=\beta_{0}+\beta_{1} \cdot 1\left[I S P_{i}>40\right]+\beta_{2} \cdot I S P_{i}+\beta_{3} \cdot I S P_{i} \times 1\left[I S P_{i}>40\right]+\beta_{4} \cdot \log (E)_{i}+\epsilon_{i}
$$

where $I S P_{i}$ is the ISP of school $i, 1\left[I S P_{i}>40\right]$ is an indicator for whether the ISP exceeds the $40 \%$ threshold, and $\log (E)_{i}$ is $\log$ enrollment. We are mainly interested in the coefficient, $\beta_{1}$, which captures any jump in the outcome variable $y_{i}$, such as ADP or CEP participation, at the discontinuity. Figure 15 presents the relationship between school ISP and CEP on the left and ADP on the right. There is a clear jump in both CEP participation and ADP rates at $40 \%$. These patterns are mirrored in the regression results, presented in table 17 . There is a 16.9 percentage point jump in the likelihood of participation under the CEP at the $40 \%$ threshold (column 2). This jump is mirrored by a 6.8 percentage point jump in ADP (column 1). These estimates imply a large impact of the CEP on lunches served; in column 3, we present the fuzzy RD estimates, which indicate that a school near the cutoff experiences a 37.5 percentage point increase in ADP when it adopts the provision. For comparison, Schwartz and Rothbart (2020) estimate that universal free lunch increases participation among non-poor students in New York City by 11 percentage points, which is 
within the $95 \%$ confidence interval that we estimate. While the difference is not statistically significant, the RD point estimate might be larger because it captures the increase in lunches served at marginal schools (with ISPs around 40\%) rather than at the average school.

Figure 15: RD Graphs for Wisconsin

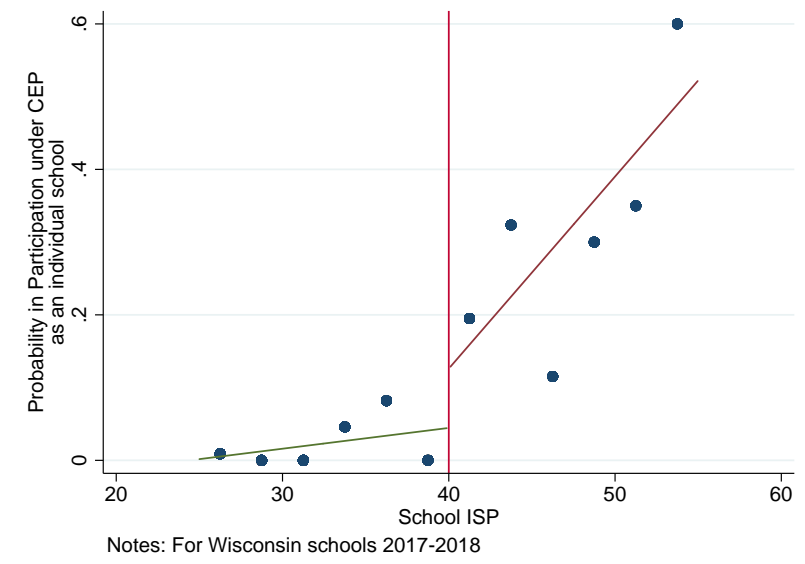

(a) Participation under the CEP

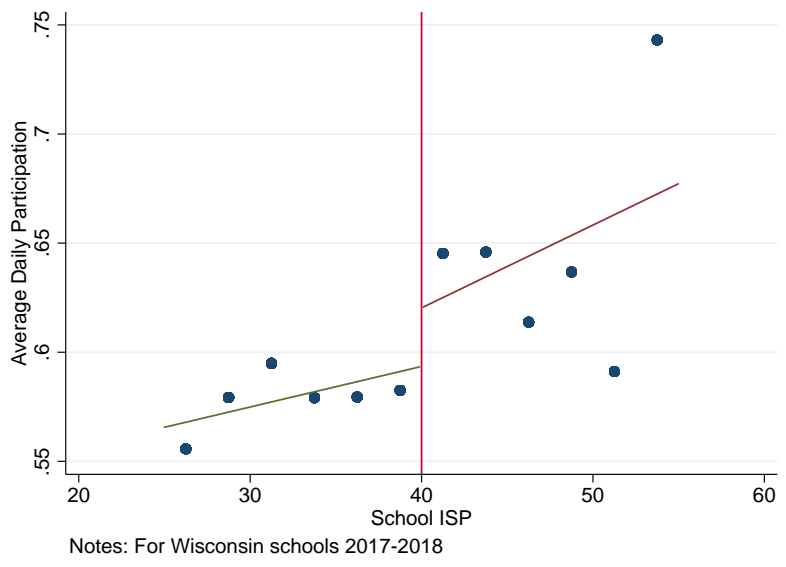

(b) Average Daily Participation in Lunch

Table 17: RD Estimates of CEP on Lunches Served

\begin{tabular}{lccc}
\hline \hline & Reduced Form & First Stage & IV \\
& $(1)$ & $(2)$ & $(3)$ \\
& ADP & CEP & ADP \\
\hline RD_Estimate & $0.068^{* *}$ & $0.169^{* *}$ & $0.375^{*}$ \\
& $(0.029)$ & $(0.070)$ & $(0.208)$ \\
\hline$N$ & 2053 & 2053 & 2053 \\
\hline \hline
\end{tabular}

Notes: This table presents results of a local polynomial regression-discontinuity design model with robust bias-corrected confidence intervals and an MSE-optimal bandwidth, estimated in Stata via the "rdrobust" command using techniques in Calonico et al. (2017). Coefficients estimate the discontinuity in ADP and CEP adoption at ISP $=40 \%$ for Wisconsin AY 2017-2018.

These estimates allow us to compute the implied own-price elasticity of school lunch as follows:

$$
\begin{aligned}
\epsilon & =\frac{66.37}{-100 \cdot \operatorname{Pr}\left\{P_{0} \neq 0\right\}+0 \cdot \operatorname{Pr}\left\{P_{0}=0\right\}} \\
& =\frac{66.37}{-100 \times .6} \\
& =-1.11 .
\end{aligned}
$$

The numerator comes from the estimated coefficient in table 17 column 3 , scaled by the aver- 
age daily participation at non-CEP schools with ISPs between 30 and 40\%. The denominator in the average percent change in price for students at a marginally eligible school. At such a school, $40 \%$ of students already qualify for free lunch under the NSLP - for these students, there is no change in the monetary cost of lunch. For the remaining $60 \%$ of students, lunch prices fall by 100\%, regardless of whether the student qualified for reduced price lunch under the traditional NSLP. The estimates imply that demand for school lunch is elastic.

\section{B.1.1 Interactions with Share Children}

As a robustness check, we test whether the CEP has a larger effect in communities with a higher proportion of school-aged children. The idea behind the test is that equal adoption of the CEP should have a larger effect in a state like Utah, where children comprise a relatively large share of the population (1.24 children per family in 2000) compared to West Virginia (0.72 children per family in 2000). ${ }^{29}$ To operationalize this test, we use data from the 2010 census on the share of children for each ZIP code and interact this measure with our measure of CEP eligibility: schools with an ISP above $40 \%$ in years following their state's adoption of the provision.

Table 18: Summary Statistics on the Share of Children across ZIP codes

\begin{tabular}{lccccccccc}
\hline \hline & mean & $\mathrm{sd}$ & $\mathrm{p} 1$ & $\mathrm{p} 10$ & $\mathrm{p} 25$ & $\mathrm{p} 50$ & $\mathrm{p} 75$ & $\mathrm{p} 90$ & $\mathrm{p} 99$ \\
\hline Zip Kid Share & 0.17 & 0.04 & 0.06 & 0.12 & 0.15 & 0.17 & 0.19 & 0.22 & 0.25 \\
\hline $\mathrm{N}$ & 52,916 & & & & & & & & \\
\hline \hline
\end{tabular}

Notes: This table reports summary statistics for the share of the population that is under 18 years old by ZIP code from the 2010 census.

In the table below, columns 1-3 reproduce the main results on the effect of CEP eligibility on store revenue. Columns 4-6 present estimates of specification (4) with the share-kids interaction term, where the share of children is standardized. In these regressions, the coefficient on CEP adoption is large and negative, but so, too is the coefficient on the interaction term. That is, a one-standard deviation increase in the share children increases the effect of the CEP by approximately 15\%. These results bear out our hypothesis that the $\mathrm{CEP}$, in directly affecting households with children, has a greater effect on store revenues in ZIP codes with a greater share of children.

\footnotetext{
${ }^{29}$ https://www.census.gov/population/socdemo/hh-fam/tabST-F1-2000.pdf
} 
Table 19: Effect of CEP Eligibility on Revenues in Areas with High/Low Share of Children

\begin{tabular}{|c|c|c|c|c|c|c|}
\hline & $\begin{array}{l}(1) \\
\text { All }\end{array}$ & $\begin{array}{l}(2) \\
\mathrm{B} / \mathrm{L}\end{array}$ & $\begin{array}{c}(3) \\
\text { Lunch Meat }\end{array}$ & $\begin{array}{l}(4) \\
\text { All }\end{array}$ & $\begin{array}{l}(5) \\
\mathrm{B} / \mathrm{L}\end{array}$ & $\begin{array}{c}(6) \\
\text { Lunch Meat }\end{array}$ \\
\hline Store Zip CEP & $\begin{array}{c}-0.140^{* * *} \\
(0.023)\end{array}$ & $\begin{array}{c}-0.155^{* * *} \\
(0.025)\end{array}$ & $\begin{array}{c}-0.258^{* * *} \\
(0.029)\end{array}$ & $\begin{array}{c}-0.141^{* * *} \\
(0.024)\end{array}$ & $\begin{array}{c}-0.156^{* * *} \\
(0.026)\end{array}$ & $\begin{array}{c}-0.260^{* * *} \\
(0.030)\end{array}$ \\
\hline CEP x Standardized Zip Kid Share & & & & $\begin{array}{l}-0.025 \\
(0.015)\end{array}$ & $\begin{array}{l}-0.024 \\
(0.017)\end{array}$ & $\begin{array}{c}-0.057^{* * *} \\
(0.019)\end{array}$ \\
\hline F-stat & 663 & 663 & 663 & 220 & 220 & 220 \\
\hline Observations & 53,059 & 53,059 & 53,059 & 52,916 & 52,916 & 52,916 \\
\hline
\end{tabular}

Notes: Standard errors in parentheses. ${ }^{*} p<0.1,{ }^{* *} p<0.05,{ }^{* * *} p<0.01$. All regressions include a constant and store and state by year fixed effects. Standard errors are clustered at store level. Sales are aggregated to the school year, with sales from September 2014 to August 2015, for example, being associated with CEP participation in the 2014/2015 school year.

\section{B.1.2 Alternative Fixed Effects}

Our main regression specification (4) for estimating the effect of the CEP on store-level outcomes such as revenue and prices includes both store and county $\times$ year fixed effects. The aim of the county $\times$ year fixed effects is to capture any factors apart from the CEP that vary across time and space and influence grocery revenues. In essence, we compare within-store changes in revenue for stores near schools that adopt the CEP to stores near schools that do not adopt the CEP, but are located in the same county. In figure 16, we compare estimates across specifications where we allow for alternative fixed effects that allow for different control groups. As a baseline, subfigure 16a presents our preferred estimates. In subfigure $16 \mathrm{~b}$, we include state $\times$ year fixed effects, broadening the control group, but also ISP $\times$ year fixed effects that allow for different time trends for stores in high and lowincome neighborhoods. In subfigure $16 \mathrm{c}$, we keep the ISP $\times$ year fixed effects but narrow to the county $\times$ year fixed effects. The point estimates are fairly stable across specifications, suggesting that 2 years after the program, stores near schools that are individually eligible for the program to the CEP see a $2-4 \%$ drop in revenues. However, there is a semblance of a pre-trend in subfigure 16b. While parallel trends before the introduction of the CEP does not imply that our estimates are causal, they do suggest that the county $\times$ year fixed effects may play an important role in controlling for economic trends that vary geographically. 
Figure 16: Effect of CEP Eligibility on Log Grocery Revenues with Alternative FEs

(a) Store and County $\times$ Year Fixed Effects

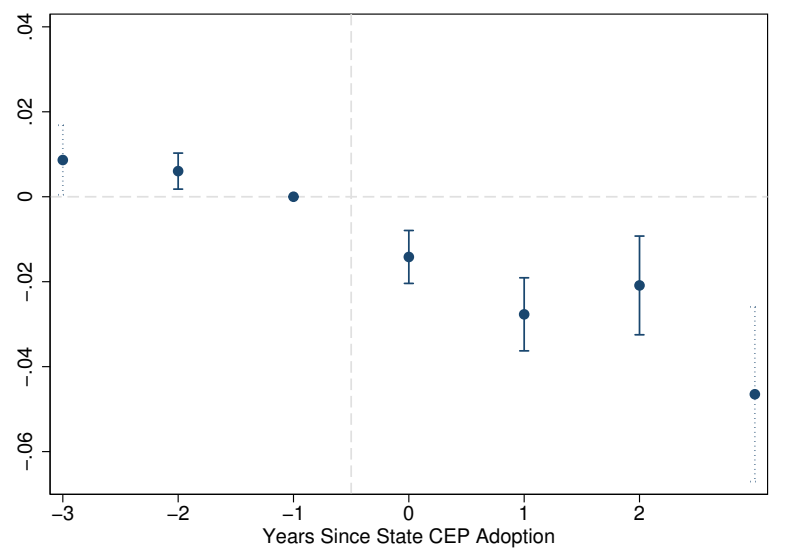

(b) Store and State $\times$ Year Fixed Effects + ISP $40 \times$ Year FE

(c) Store and County $\times$ Year Fixed Effects + ISP $40 \times$ Yr FEs
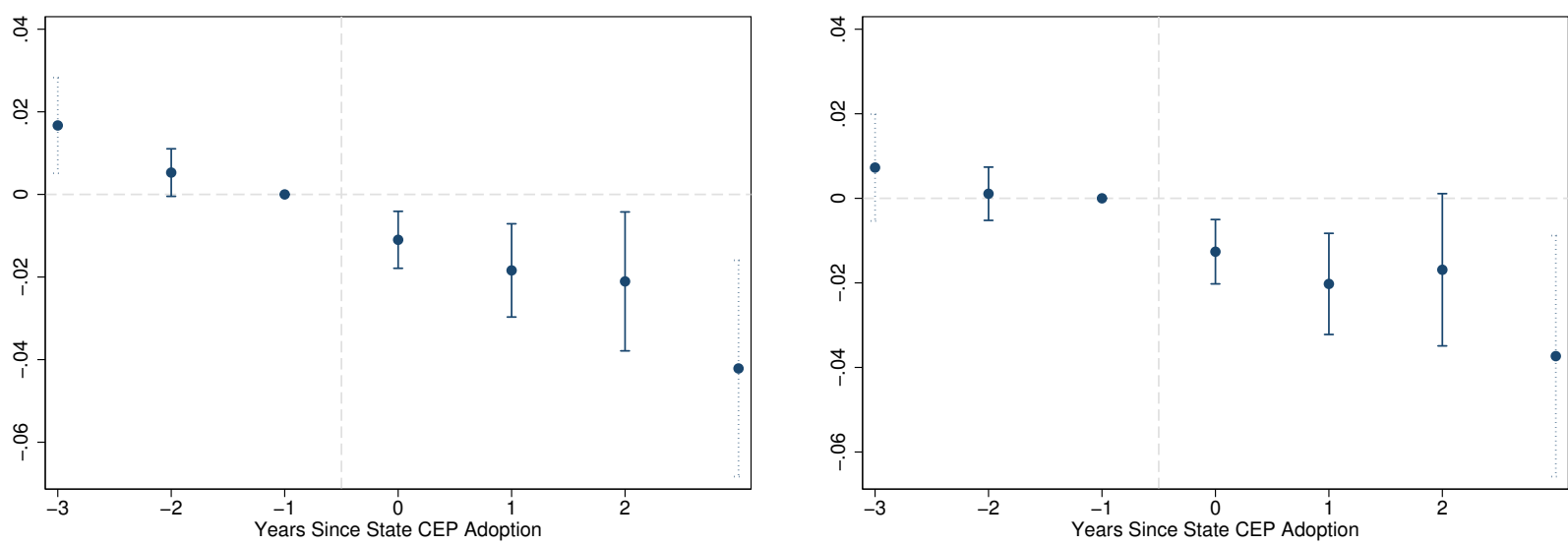

Notes: This figure plots estimates of the effect of CEP eligibility on grocery store revenues. Subfigures present estimates based on different combinations of fixed effects. Estimates with dotted confidence bands are limited to a subset of state-waves for which we observe at outcomes four years after state adoption of the CEP. The regression specification that underlies the estimates is equation 4

\section{B.1.3 Distribution across Product Groups}

This appendix section explores how the impact of the CEP is distributed across product groups. In line with our finding that the direct effect of the CEP is to induce substitution by households with children away from grocery store lunch purchases to school lunch, we expect that grocery retailers experience the largest revenue declines among products that particularly appeal to households with children. To test this hypothesis, we construct a family-appeal variable, which we measure as the pre-CEP share of expenditures in a product group attributed to households with school-aged children. We then adapt our difference-indifferences specification (4) so that revenues are measured at the product group level and 
our explanatory variables include a triple interaction between family-appeal, state adoption, and school eligibility. Figure 17 plots an event study separately for product groups with below- and above-median family appeal. Consistent with our conjecture, revenue declines are steeper for products with above-median family appear. Note that other groups also experience a decline, which is in keeping with our evidence that households take fewer trips to grocery stores following CEP adoption.

Figure 17: Revenue Effects across Product Groups

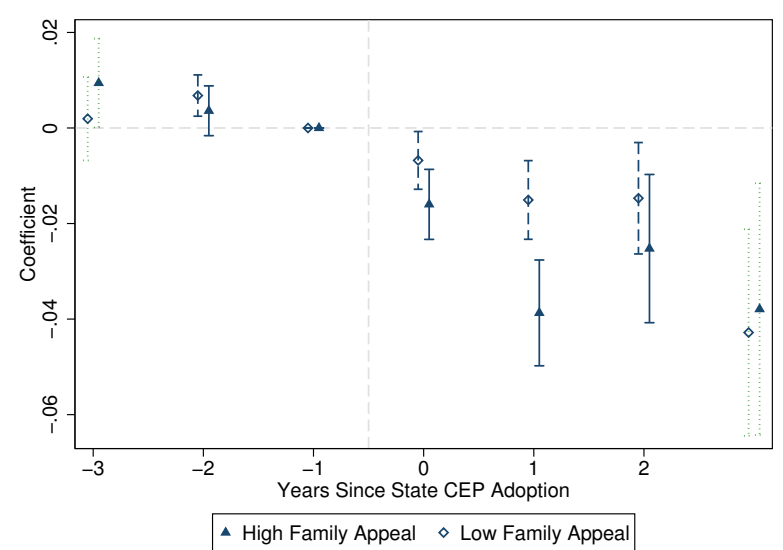

Notes: This figure plots estimates of the effect of CEP eligibility on grocery store revenues in product groups with above and below median family appeal. Estimates with dotted confidence bands are limited to a subset of state-waves for which we observe at outcomes four years after state adoption of the CEP. The regression specification that underlies the estimates is identical to equation 4 , but with each set of fixed effects (store and county-by-year) interacted with product group and the time since state CEP adoption indicators interacted with both school eligibility and an indicator for whether the 2010 share of HMS expenditure in a product group that was by households with school-age children.

\section{B.1.4 Event-by-Event Analysis}

In this appendix, we replicate our difference-in-differences specification (4) estimating the revenue effects by wave of state CEP adoption. In each event study, the sample only includes stores in states that adopted in the same academic year, so that the control group comprises only stores that are never-treated. As described in Cengiz et al. (2019), the virtue of this alternative specification is that it robust to treatment effect heterogeneity. The results are qualitatively similar across waves, with reduced-form revenue declines between 3-8\% (the intent-to-treat effect). 
Figure 18: Revenue Effects By Year of Adoption

(a) Wave 1 (3 States)

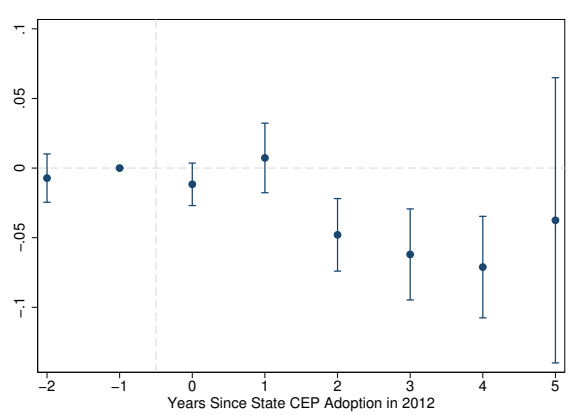

(c) Wave 3 (4 States)

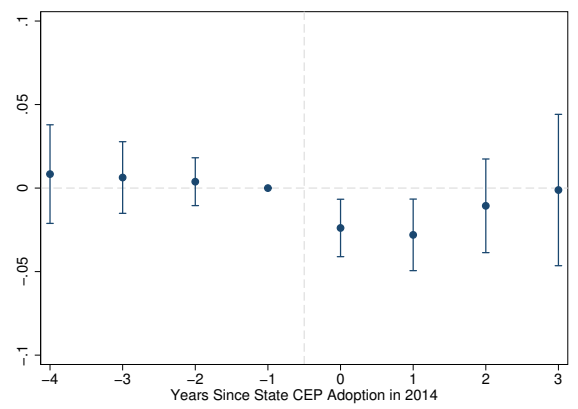

(b) Wave 2 (3 States + DC)

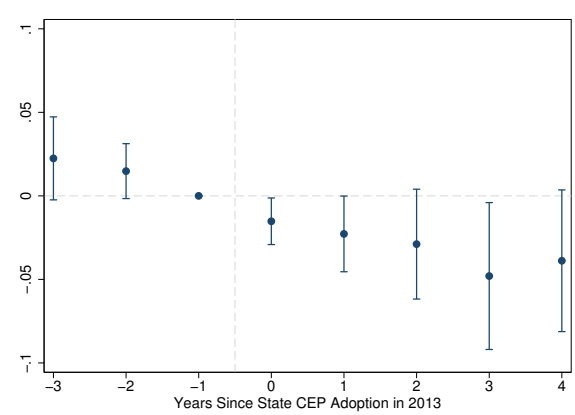

(d) Wave 4 (All Other States)

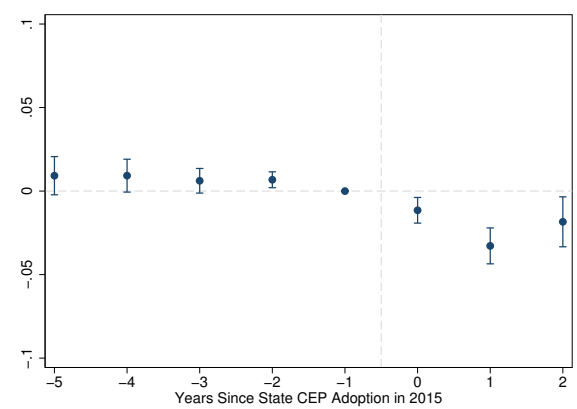

Notes: This figure plots estimates of the effect of CEP eligibility on grocery store revenues in sets of states that adopted the CEP program in different years. The regression specification that underlies the estimates is identical to equation 4 but with a different sample of stores in each regression. Table 1 provides information on the timing of state CEP adoption. 